\title{
AN EXPLORATION OF INCORPORATING SITE RESPONSE INTO PSHA Part II: Sensitivity of Hazard Estimates to Site Response Approaches
}

\author{
Myrto Papaspiliou, Stavroula Kontoe*, Julian J. Bommer \\ Department of Civil and Environmental Engineering, Imperial College London, UK
}

\begin{abstract}
This paper examines the sensitivity of seismic hazard analyses to various site response analysis procedures. Site effects are incorporated in the hazard calculations using a probabilistic approach and specifically the methodology of Bazzurro and Cornell [1] for the transformation of a generic ground-motion prediction equation to a site-specific one. The paper explores the sensitivity of the median amplification function, its standard deviation and the resulting surface hazard curve, to different methods of site response analysis and model input parameters. The computed site-specific surface hazard curves are also compared with those obtained from a generic soil ground-motion prediction equation. For the two sites investigated, it is shown that the choice of equivalent linear or nonlinear analysis with different constitutive model parameters has a large impact on the hazard results. The sandy site was seen to be more sensitive to the site response analysis approach employed than the clayey site.
\end{abstract}

Keywords: PSHA, Site response, Ground-motion prediction, Uncertainties

\section{Introduction}

The importance of incorporating site effects in hazard analyses using a probabilistic framework has been highlighted by numerous researchers [e.g., 1, 2, 3], as failure to do so can lead to unconservative hazard estimates and surface ground motions with unknown rates of exceedance. Among different methodologies that have been developed, an approach by Bazzurro and Cornell [1] is particularly promising. The methodology allows site effects to be included in the hazard calculations, following the performance of the site response analysis using a small number of ground-motion records, by simply transforming a rock ground-motion prediction equation (GMPE). This approach has a number of advantages as the transformation of the GMPE is relatively straightforward and it can take into account all uncertainties associated with the site response analysis.

Bazzurro and Cornell [4] used an inelastic constitutive reduced-order bounding-surface model and the finite element software SUMDES [5] for the performance of the site response analyses. However, many different models are available to practitioners, with equivalent linear analysis, in particular, often being dominant. This paper explores the sensitivity of the methodology and of the resulting surface hazard curve to different choices associated with the performance of the site response analysis. The paper initially investigates the sensitivity of the median amplification function and its standard deviation to different site response analysis choices. Site response analysis has been performed using both equivalent linear and nonlinear methodologies, different dynamic soil properties curves and different model calibration parameters [6]. Subsequently, the site amplification functions are used to transform the Abrahamson and Silva [7] rock GMPE and the

\footnotetext{
* Corresponding author: Tel: +44-20-7594-5996, Fax: +44-20-7594-5934, Email: $\underline{\text { Stavroula.kontoe@imperial.ac.uk }}$
} 
sensitivity of the PSHA results is explored. PSHA has been performed for a number of locations in California.

\section{Incorporation of Site-Specific Effects in PSHA}

\subsection{Transformation of a Rock Ground-Motion Prediction Equation}

Producing a GMPE for a particular soil condition or site of interest requires a significant number of rock ground-motion accelerograms to be driven through a model of the soil profile. This makes this approach difficult and time consuming to implement. The methodology proposed by Bazzurro and Cornell [1] aims to transform an existing rock GMPE to a soil-specific one using a much smaller number of records by defining and using a site-specific amplification function. This paper utilises the aforementioned approach, modified to include a more complex regression model that accounts for the nonlinearity between the soil amplification and the input ground-motion. The amplification function, $A F(f)$, is thus defined as:

$$
\ln A F(f)=c_{0}+c_{1} \ln \left(S_{a}^{r}(f)+c_{2}\right)+\varepsilon_{\ln A F(f)} \sigma_{\ln A F(f)}
$$

where $S_{a}^{r}(f)$ is the rock spectral acceleration, $c_{0}, c_{1}$ and $c_{2}$ are the regression constants, $\varepsilon_{\ln A F(f)}$ is the standard normal variable and $\sigma_{\ln A F(f)}$ is the standard error of estimation resulting from the regression. The nonlinear regression results can be used to transform a ground-motion prediction equation, whose median surface spectral acceleration, $\widehat{S_{a}^{s}(f)}$, will be given by:

$\ln \widehat{S_{a}^{S(f)}}=\ln \widehat{S_{a}^{r}(f)}+c_{0}+c_{1} \ln \left(\widehat{S_{a}^{r}(f)}+c_{2}\right)$

where $\widehat{S_{a}^{r}(f)}$ is the median rock spectral acceleration as given by a suitable GMPE, while its associated standard deviation is now estimated as:

$\sigma_{\ln S_{a}^{S}(f)}=\sqrt{\left(\frac{c_{1} \cdot S_{a}^{r}(f)}{c_{2}+S_{a}^{r}(f)}+1\right)^{2} \cdot \sigma_{\ln S_{a}^{r}(f)}^{2}+\sigma_{\ln A F(f)}^{2}}$

Equations (2) and (3) allow the transformation of a generic GMPE into a site-specific one by coupling the existing rock equation with the site-specific regression. The result of the above transformation is that the uncertainties associated with the site response analysis are also taken into consideration when incorporating site effects in PSHA. Due to nonlinearity in the soil behaviour, the slope of $A F(f)$, given by $\left[c_{1} \cdot S_{a}^{r}(f)\right] /\left[c_{2}+S_{a}^{r}(f)\right]$, often takes negative values. Therefore, the standard deviation of the surface spectral acceleration can be reduced compared to that of the bedrock. The modified GMPE can subsequently be used directly for the estimation of the hazard at the site of interest. It is important that a sufficient number of records are used in the performance of the site response analysis to allow a reliable estimation of the amplification function and to capture the ground-motion variability.

\subsection{Impact of Site Response Analysis Approach on $A F(f)$}

The methodology discussed allows the incorporation in the hazard calculations of all uncertainties associated with the site response (e.g., ground-motion variability, shear-wave velocity profile or dynamic soil properties uncertainties). However, the variability associated with the soil properties is of secondary importance compared to that associated with the ground-motion records [4] and hence, in this study, only the latter is considered. In our companion paper [6] we performed a number of site response analyses using 120 ground-motion records and examined the sensitivity 
of the ground response estimation to different methods and parameter selections. Herein, we initially examine the impact of such choices on the median amplification function and its standard deviation. Table 1 summarises the site response analyses performed. The two investigated sites have almost identical average shear-wave velocities in the upper $30 \mathrm{~m}, V_{s 30}$, and hence any generic site factors classifying sites based on $V_{s 30}$ would predict the same amplification for both. The performance of the site-specific site response analysis using the same ground-motion dataset allows the comparison between the amplification functions of the two sites and the evaluation of the adequacy of $V_{s 30}$ as an amplification predictor. Moreover, it is noted that the study has used 120 ground-motion records for validation purposes, while the methodology can be applied using a much smaller number [4]. Details regarding the selected ground-motion records and the soil stratigraphies of the investigated sites can be found in Papaspiliou et al. [6].

Table 1: Summary of parameter selection for nonlinear site response analyses performed.

\begin{tabular}{llllll}
\hline $\begin{array}{l}\text { Model } \\
\text { number }\end{array}$ & $\begin{array}{l}\text { Model } \\
\text { Acronym }\end{array}$ & $\begin{array}{l}\text { Method of } \\
\text { Analysis }\end{array}$ & Target curves & $\begin{array}{l}\text { Selection of } \\
\text { fitting } \\
\text { parameters }\end{array}$ & $\begin{array}{l}\text { Viscous } \\
\text { formulation }\end{array}$ \\
\hline 1 & EQLIN-S & SHAKE91 & Seed et al. (1986) & - & - \\
2 & EQLIN-I & SHAKE91 & Ishibashi and Zhang (1993) & - & - \\
3 & EQLIN-D & SHAKE91 & Darendeli (2001) & - & - \\
4 & NON-S_SR1 & DMOD2000 & Seed et al. (1986) & Fit 1 & Simplified Rayleigh \\
5 & NON-D_SR1 & DMOD2000 & Darendeli (2001) & Fit 1 & Simplified Rayleigh \\
6 & NON-D_FR1 & DMOD2000 & Darendeli (2001) & Fit 1 & Full Rayleigh \\
7 & NON-D_FR2 & DMOD2000 & Darendeli (2001) & Fit 2 & Full Rayleigh \\
\hline
\end{tabular}

\subsubsection{Sensitivity of the median amplification function $A F(f)$}

A nonlinear regression in the logarithmic space is performed for each set of site response analysis and across a range of spectral periods. In a number of cases the regression was poorly constrained with the parameters showing relatively large estimation uncertainties. In such cases, different values of $c_{2}$ were fixed during the regression of the other parameters. A typical example of the regression results is shown in Table 2, for the NON-D_FR2 analysis of the sandy site, SCH. The amplification factors are plotted in Fig. 1 together with the median, +/- standard deviation amplification functions and the $95 \%$ confidence intervals.

Table 2: Model parameters for NON-D_FR2 analysis

\begin{tabular}{llllllll}
\hline Period & $\mathrm{c}_{0}$ & Std. error & $\mathrm{c}_{1}$ & Std. error & $\mathrm{c}_{2}$ & Std. error & Std. Dev. \\
\hline 0.01 & 0.089 & 0.023 & -0.708 & 0.051 & 0.5 & - & 0.170 \\
0.2 & 0.368 & 0.017 & -0.646 & 0.034 & 0.5 & - & 0.185 \\
0.8 & 0.617 & 0.014 & -0.429 & 0.028 & 0.5 & - & 0.127 \\
1.0 & 0.647 & 0.019 & -0.145 & 0.04 & 0.5 & - & 0.162 \\
1.5 & 0.707 & 0.041 & 0.092 & 0.033 & 0.022 & 0.038 & 0.166 \\
3.0 & 0.419 & 0.062 & 0.244 & 0.035 & 0.5 & - & 0.189 \\
\hline
\end{tabular}

Figure 2 shows the median site amplification functions for all sets of analyses. Differences are generally more pronounced at shorter periods, although relatively large variability arises in the intermediate period range as well, mostly between the equivalent linear and nonlinear analyses. As expected, the variability is higher in the large spectral acceleration range since at this range greater differences in the ground response estimates were observed [6].

In the short period range, the NON-D_SR1 analysis predicts significantly lower amplification across almost the entire acceleration range. The use of the simplified Rayleigh formulation, together with the higher damping for strains larger than about $0.3 \%$ associated with calibration Fit 1 , lead to the lower $A F(f)$ observed in Fig. 2 for periods $\mathrm{T}=0.01 \mathrm{~s}$ and $0.2 \mathrm{~s}$. At longer 
periods, all four sets of nonlinear analyses result in almost identical amplification functions in the low rock acceleration range, with differences increasing as accelerations exceed $0.1 \mathrm{~g}$. As expected, the Rayleigh damping formulation has no impact on $A F(f)$ for periods longer than $0.2 \mathrm{~s}$, with the NON-D_SR1 and NON-D_FR1 curves being identical for the longer periods. The amplification function resulting from the NON-D_FR2 analysis tends, for the majority of the acceleration range, to be higher than the rest of the nonlinear analysis functions and with a milder slope, as it employs the lowest damping of all.

Focusing on the equivalent linear analyses, significantly different patterns are observed among the examined periods. Comparison of the amplification functions arising from the two methodologies shows that, in the short-period range, equivalent linear analyses tend to lead to higher amplification. At periods beyond the elastic site period $(0.76 \mathrm{~s})$, large differences are still observed among the three equivalent linear functions, whereas the nonlinear analyses at this range have started converging. EQLIN-I and EQLIN-D analyses result in functions that shift upwards in the high acceleration range. Despite some similarities noted between EQLIN-D and NON-D_FR2, important limitations of the equivalent linear methodology make it unsuitable for the estimation of the amplification across the entire acceleration and period range. The inability of the methodology to converge to a solution for a number of the higher intensity records causes the unexpected upward shift of the amplification function at the intermediate and longer periods, which is particularly evident at $\mathrm{T}=0.8$ and $1.0 \mathrm{~s}$.

The convergence problem was mostly encountered for the relatively strong records, as discussed in Papaspiliou et al. [6]. This is observed in the panels of Fig. 3, where in the case of EQLIN-S the records span up to a spectral acceleration $S_{a}{ }^{r}(0.8 s)$ of about $3 \mathrm{~g}$, while in the cases of EQLIN-I and EQLIN-D the highest values encountered are approximately $1.2 \mathrm{~g}$ and $0.8 \mathrm{~g}$ respectively. At $\mathrm{T}=0.8 \mathrm{~s}$ EQLIN-S shows a kink in the amplification function for records with $S_{a}^{r}(0.8 s)$ between $0.1 \mathrm{~g}$ and $0.5 \mathrm{~g}$. Similarly, in the case of $\mathrm{T}=1.0 \mathrm{~s}$ a kink is observed for $S_{a}^{r}(1.0 s)$ values between 0.2 and $0.6 \mathrm{~g}$.

The predominant elastic period of vibration for the examined stratigraphy (based on the average shear-wave velocity) is $0.76 \mathrm{~s}$, which during intense shaking increases to longer periods, depending on the induced strains. Based on the average converged (equivalent linear) stiffness of the soil layers, records with $S_{a}{ }^{r}(0.8 s)$ values between 0.1 and $0.5 \mathrm{~g}$ shifted the site period to elongated values between 0.8 and $0.9 \mathrm{~s}$. As a result, resonance with the elongated site period takes place for these records, leading to the larger amplification in this range. For records with higher accelerations, resonance is not exhibited at that period range and the amplification is reducing, consistent with nonlinear soil behaviour. In the cases of EQLIN-I and EQLIN-D, however, most of the higher intensity records have been excluded prior to the regression due to the inability of the method to converge. As a result, the amplification due to the resonance with the elongated site period dominates the regression. The employed functional form for the description of $A F(f)$ is unable to capture this kink observed in EQLIN-S. Simultaneously, the amplification at the lower acceleration range is overestimated, as the kink drives the entire curve upwards. The use of a more complex functional form could produce a better estimate of the soil response in the intermediate period range. However, a more complex form, with a larger number of parameters, would be very difficult to constrain by the regression, particularly when a relatively small number of records are used for the analyses. This highlights the importance of using records in the site response analysis which capture the entire acceleration range considered in PSHA and it gives an indication of the impact the ground-motion selection has on the median $A F(f)$.

The median amplification functions for the clayey site (NES) are shown in Fig. 4. In this case, the differences among the various analysis approaches are smaller. Similarly to the alluvial site case, the NON-D_FR2 analysis leads to an amplification function that, for PGA $>0.2 \mathrm{~g}$, varies considerably from the other nonlinear analyses, due to the lower damping assumed in the intermediate-to-high strain range. Differences are smaller for $\mathrm{T}=0.2 \mathrm{~s}$, with the NON-D_SR1 analysis predicting the lowest amplification, as expected and discussed already. 
Differences between the equivalent linear and nonlinear analyses are considerably smaller in the case of the NES. Clayey soils exhibit slower stiffness degradation and their behaviour is less nonlinear. As a result, the equivalent linear analysis often converged at relatively smaller strains, compared to those exhibited in the case of the $\mathrm{SCH}$ site, where the simplifying assumptions of equivalent linear analysis are still appropriate, making the method's predictions comparable to those of nonlinear analysis. The stronger linearity of clay sites, compared to that of sandy sites, also justifies the pronounced amplification observed at the lower intensity range for $\mathrm{T}=1.0 \mathrm{~s}$, where resonance with the elastic site period $(0.98 \mathrm{~s})$ is taking place.

\subsubsection{Sensitivity of the standard deviation, $\sigma_{\ln A F(f)}$}

One of the most important advantages of the examined methodology is that it allows the incorporation of uncertainties associated with the site response analysis into PSHA. Therefore, it is of interest to this study to examine not only the effect of the site response analysis on the median amplification function, but also on its standard deviation. The standard deviations $\sigma_{\ln A F(f)}$ obtained from the different sets of analysis for each site are presented in Fig. 5. It is observed that $\sigma_{\ln A F(f)}$ does not exceed 0.3 for any spectral period or site response analysis approach. This is in accordance with Bazzurro and Cornell [4] who found similar levels of variability when the amplification is estimated as a function of the rock spectral acceleration. In fact, with the exception of the $\sigma_{\ln A F(f)}$ at $0.2 \mathrm{~s}$ associated with the equivalent linear analyses, the standard deviation mostly varies between 0.1 and 0.2. In a number of cases $[$ e.g., 8,9$]$ a value of 0.3 is being used as a typical level of variability of $\ln A F(f)$. The use of an arbitrary, and possibly inflated, level of aleatory variability associated with the amplification function is clearly inappropriate, as it can result in undermining an important advantage of the methodology.

Comparison of $\sigma_{\ln A F(f)}$ for EQLIN-S, EQLIN-I and EQLIN-D analyses for SCH reveals that, across the majority of periods, there are small differences, with the standard deviation associated with the EQLIN-S analysis being generally higher than the other two (except for $\mathrm{T}=0.01 \mathrm{~s}$ ). Figure 6 a shows the median amplification function for EQLIN-S at $0.2 \mathrm{~s}$ and Fig. $6 \mathrm{~b}$ the residuals of the regression analysis. The residuals show that the scatter increases considerably for $S_{a}{ }^{r}(0.2 s)$ values larger than approximately $1 \mathrm{~g}$. EQLIN-I and EQLIN-D contain only few records with such high acceleration levels, which explains the lower values of $\sigma_{\ln A F(f)}$. Indeed, if the higher acceleration records are excluded from the EQLIN-S dataset, the standard deviation drops significantly to just 0.115 for $\mathrm{T}=0.2 \mathrm{~s}$. Furthermore, it is important to note that the increase in residuals observed for high $S_{a}^{r}(0.2 s)$ values is not observed for any of the other spectral periods or for the nonlinear analyses. A similar strong increase is noted in the standard deviation of the equivalent linear analyses for $\mathrm{T}=0.2 \mathrm{~s}$ of site NES (Fig. $5 b$ ).

The results of the analyses from both sites indicate that equivalent linear analysis is more sensitive to the input ground motions, and in particular in the case of high-intensity records. The sensitivity of the methodology to the characteristics of the input ground motions, evident from the increase in the scatter observed for $\mathrm{T}=0.2 \mathrm{~s}$, is another important limitation of the equivalent linear analysis as it implies the need for the use of a larger number of ground-motion records for the stable estimation of the median amplification function and its standard deviation than in nonlinear analysis. This is particularly important for structures for which the short-period range is of significant interest as well, such as nuclear power plants. The nonlinear analyses tend to have slightly lower standard deviations than the EQLIN-S analysis. Nevertheless, the benefit of the former can only be truly evaluated based on the standard deviation of the surface spectral acceleration, where the effect of the slope of $A F(f)$ can also be taken into account. 


\subsubsection{Comparison of the amplification functions for the two sites}

The two examined soil stratigraphies have almost identical $V_{s 30}$, at $280 \mathrm{~m} / \mathrm{s}$ and $284 \mathrm{~m} / \mathrm{s}$. Comparing the amplification functions for the two sites reveals the significant differences in the behaviour of sandy and clayey sites, which cannot be captured by typical site generic approaches. Additionally, the generic approaches are clearly not able to capture any particular site characteristics, such as amplification peaks at the site period. Variation in the amplification of the two sites is particularly evident in the intermediate period range (Fig. 7). The largest differences are noted at $\mathrm{T}=1.0 \mathrm{~s}$ both due to differences in the dynamic behaviour of sandy and clayey sites, as well as the resonance taking place at the predominant site period for site NES. However, significant variation is also observed at $\mathrm{T}=1.5 \mathrm{~s}$ verifying that clayey soils tend generally to amplify long-period motions more.

Inevitably, the striking differences in the median amplification functions for the two sites prompt another question: how well can generic site factors and existing classification systems capture the behaviour of the two sites? Figure 8 presents the comparison of the Eurocode 8 (EC8) [10] and NEHRP [11] generic amplification factors to the site-specific results for 0.2 and $1 \mathrm{~s}$. The EC8 factor underestimates considerably the amplification in the low acceleration range for $\mathrm{T}=0.2 \mathrm{~s}$, while its inability to capture soil nonlinearity means that it considerably overestimates the site amplification for $S_{a}^{r}(0.2 s)$ higher than about $0.5 \mathrm{~g}$. At $1.0 \mathrm{~s}$, EC8 is unable to capture the amplification observed in either of the two sites across the entire acceleration range. The discrepancy is even worse for NES due the resonance with the elastic site period.

The NEHRP site factors [11] are able to capture the soil response considerably better. They predict slightly lower amplification in the low-acceleration range for the shorter periods, while for $S_{a}{ }^{r}(0.2 s)$ between 0.2 and $1.25 \mathrm{~g}$ they are seen to match the site-specific results very well. As expected, at $\mathrm{T}=1.0 \mathrm{~s}$ they are unable to capture the increased amplification for the clayey site, while for $\mathrm{SCH}$ they lie slightly above those from the site-specific approaches. Last but not least, it needs to be highlighted that the use of both EC8 and NEHRP site factors implies that the variability for rock and soil categories is identical whereas a number of studies have shown the above assumption to not be generally true [e.g., 12].

\section{Transformation of a rock GMPE}

The Bazzurro and Cornell [1] methodology has been applied to transform the Abrahamson and Silva [7] rock ground-motion prediction equation using the Attenuation Equation Plotter application of the open-source software OpenSHA [13].

\subsection{Transformation of the median spectral acceleration}

The median surface spectral accelerations for site $\mathrm{SCH}$, as predicted by the modified GMPEs, are shown against distance from the rupture plane, $r_{\text {rup }}$, for two magnitudes and different spectral periods in Fig. 9. Similarly, Fig. 10 presents the corresponding results for the clayey site. In both figures the generic GMPEs of Abrahamson and Silva [7] (AS97), for both rock and soil conditions, are also shown.

In the case of $\mathrm{SCH}$, differences are more pronounced for PGA and 0.2s. For the $\mathrm{M}=6$ event, the largest differences are observed for distances less than about $20 \mathrm{~km}$, whereas for the larger magnitude $(M=8)$, significant variability is noted across almost the entire distance range. For $M=6$, the generic soil AS97 equation predicts lower spectral accelerations than all the transformed equations across the entire distance range, with the exception of $\mathrm{T}=1.5 \mathrm{~s}$. This is still true for the larger magnitude event, where in the range of soil amplification $\left(P G A_{r}<0.3 \mathrm{~g}, S_{a}^{r}(0.2 s)<0.7 \mathrm{~g}\right)$, AS97 predicts considerably smaller surface motions than the site-specific equations. At higher ground 
shaking levels, the predictions by AS97 seem to be in better agreement with those of the sitespecific equations.

In the case of NES, smaller variability is observed among the results, as already noted from the inspection of the amplification functions. In the case of the magnitude 6.0 event, differences among the medians of the transformed equations are noted only for PGA and 0.2s. The AS97 soil equation is seen again to predict lower spectral acceleration levels than most of the site-specific equations. This is expected since the clayey site was seen to amplify ground motions more than the sandy site, especially in the long-period range.

\subsection{Transformation of the standard deviation term, $\sigma_{l n S a} a_{(f)}$}

Figures 11 and 12 compare the standard deviations of the generic and site-specific equations $\left(\sigma_{l n S a}{ }^{s}(f)\right)$ for the two sites. The standard deviation of the AS97 equations is magnitude dependent, but independent of the site class. However, real recordings on rock and soil have shown a reduction in the variability of $S_{a}^{s}(f)$ compared to that of $S_{a}^{r}(f)$ and some of the recent NGA equations have incorporated standard deviation terms that are also dependent on $V_{s 30}$.

Figure 11 shows a large reduction in the standard deviation of the surface spectral acceleration for shorter distances, while for distances larger than about 50km, the standard deviations of rock and soil-surface motions are almost the same. This reduction is noted for periods up to $1.0 \mathrm{~s}$, while an increase compared to rock is observed at $\mathrm{T}=1.5 \mathrm{~s}$ for all methods of site response analysis. Particularly interesting are the results at $\mathrm{T}=1.0 \mathrm{~s}$, with all equivalent linear analyses causing an increase in $\sigma_{\operatorname{lnSa}(f)}^{s}$. This increase is associated with the positive $c_{1}$ values and upward sloping $A F(f)$ noted in the case of the equivalent linear analyses for $\mathrm{T}=1.0 \mathrm{~s}$ as discussed earlier. The differences among the various site response analysis results vary with distance and are more pronounced in the case of the magnitude 8.0 event. For small distances $(<20 \mathrm{~km})$, the different site response analyses lead to standard deviations that vary between 0.2 and 0.35 for PGA and between 0.5 and 0.7 for $\mathrm{T}=1.5 \mathrm{~s}$. Such variation in $\sigma_{l n S a}{ }^{s}(f)$ is expected to have a considerable impact on the surface hazard curves.

In the case of the clayey site, similar reductions in $\sigma_{\operatorname{lnSa} a_{(f)}}$ compared to the AS97 equations are observed (Fig. 12). On the other hand, slightly smaller variability is noted among the various site-specific ground-motion prediction equations. Clearly, the transformation of the rock GMPE to include the site-specific effects can lead to a considerable reduction in the variability of the surface ground-motions compared to rock, as a result of sediment nonlinearity. As the AS97 equations do not distinguish between the standard deviation of rock and soil sites, the benefit of the site-specific analysis is straightforward. The same is true for the NEHRP site factors. Most of the more recently developed NGA equations [14] have incorporated, in addition to the nonlinear site amplification functions, different levels of variability depending on $V_{s 30}$ and shaking intensity. Comparison of the rock and soil standard deviations of the Abrahamson and Silva [9] equations (AS08) for a magnitude 7.0 event, with the results obtained from the site-specific equations for the two sites (Fig. 13), reveals that the latter result in lower values across the majority of the distance range. The effects are clearly more significant for smaller distances.

The two Abrahamson and Silva equations employ different $\sigma_{\operatorname{lnSa}}{ }^{r}(f)$ values, with the AS08 equation showing increased levels of variability for rock sites. Furthermore, the AS08 equations have used a constant value of 0.3 for $\sigma_{\ln A F(f)}$ which is generally higher than the levels of variability found for the amplification functions in this study. For comparison purposes, the AS97 rock equation is transformed using the procedure employed so far in this study, but now $\sigma_{\ln A F(f)}$ is fixed to 0.3, while the remaining regression parameters are kept intact. The results (Fig. 14) clearly show an increase in $\sigma_{\operatorname{lnSa}(f)}{ }^{s}$ compared to Fig. 13 and a much greater similarity to the AS08 soil standard deviation for both sites. It is evident that the aleatory variability associated with $\ln A F(f)$ has a considerable impact on the results and it is therefore crucial that it be properly captured. 


\section{Probabilistic Seismic Hazard Analysis}

Probabilistic seismic hazard analyses were performed for a number of locations in California, assuming the stratigraphies of the Sylmar County Hospital and Nesher sites are encountered there. For all analyses the transformed GMPEs described in Section 3 and the original AS97 equations were used. The PSHA was performed with the open-source software OpenSHA [13] which allows the estimation of the seismic hazard at a number of locations in California. For all cases the USGS/CGS 2002 earthquake rupture forecast and the Frankel et al. [15] fault model were used.

\subsection{Location 1: Lancaster $\left(\mathrm{N} 34.696^{\circ}, \mathrm{W}^{2} 18.135^{\circ}\right)$}

The first location examined lies approximately $15 \mathrm{~km}$ from the San Andreas fault and, therefore, the hazard at the site is expected to be dominated by the occurrence of an event across the San Andreas fault system. The hazard curves for SCH are shown in Fig. 15 for PGA and the 5\% damped pseudo spectral acceleration at different spectral periods. Overall, considerable variability is observed among the results, across most of the examined periods. Indicatively, at the $10 \%$ probability of exceedance in 50 years level, PGA varies between 0.38 and $0.7 \mathrm{~g}$, while $S_{a}^{s}(1.0 s)$ varies between 0.8 and $1.4 \mathrm{~g}$. As expected, the variability increases with decreasing annual probability of exceedance (PE) levels and at $2 \%$ probability of exceedance (PE) in 50 years, the aforementioned intensity measures vary between 0.5 and $1.0 \mathrm{~g}$ and between 1.4 and $2.6 \mathrm{~g}$, respectively.

In Fig. 9 we saw that in the short-period range the site-specific GMPEs tend to predict larger amplification and surface ground motions than the AS97 soil equation. At the same time, they have a lower standard deviation compared to rock as a result of accounting for the soil nonlinearity. Figure 15 shows that for a $10 \%$ PE in 50 years and periods up to 1.0 s the surface motions predicted by the site-specific equations are always higher than the AS97 soil equation, despite the reduced standard deviations.

Performing a disaggregation analysis $[$ e.g., 16] allows the identification of the dominant hazard scenario for the site under examination and facilitates the interpretation of the results of the hazard analysis. At relatively high annual PE levels (10\% in 50 years), it is seen in Fig. 16a that the hazard at the site is dominated by the occurrence of a magnitude 7.0-8.0 event, at a distance of $15 \mathrm{~km}$ with $\varepsilon$ close to 0.5 . At $2 \%$ PE in 50 years (Fig. 16b) the hazard is dominated by a similar magnitude-distance event, but a higher $\varepsilon$ value $(\varepsilon \sim 1.50)$ reflecting the much rarer ground motion realisation. For such a scenario significant variation among the different GMPEs both in the median surface accelerations and standard deviations were observed, justifying the differences among the hazard curves. At the $2 \% \mathrm{PE}$ in 50 years, the increase in the variation of the intensity measure estimates is driven considerably by the differences in the standard deviations of the GMPEs. The $\sigma_{l n s a}^{s}(f)$ values for the seven sets of site-specific analyses at short periods ranged from 0.2 to 0.5 (ln units).

The convergence issues of the equivalent linear analysis and the upward sloping $A F(f)$ of EQLIN-I and EQLIN-D have a profound effect on the PSHA results, as seen in Fig. 15 for T=0.8s. The positive slope of $A F(f)$ affects the median as well as the standard deviation of the transformed GMPE, which is now higher than that of rock. The above two factors lead to the significantly higher hazard estimates by these two analyses, particularly at the predominant site period, verifying the importance of issues associated with the equivalent linear analysis and the range of rock spectral accelerations considered.

In the case of the clayey site conditions the results, shown in Fig. 17, are in better agreement with each other, which to a large extent is due to the better performance of the equivalent linear methodology. The median spectral acceleration estimates of the various site-specific GMPEs for the hazard dominating scenario are almost identical for periods longer than 1.0s. Nevertheless, the standard deviation has shown considerable variation, particularly at PGA and $\mathrm{T}=1.0 \mathrm{~s}$, which leads 
to the observed differences among the hazard curves. At the predominant site period, although the site-specific analyses are capable of capturing the increased amplification due to resonance, the considerable reduction in $\sigma_{\operatorname{lnSa}(f)}^{s}$ leads to hazard curves that, with the exception of EQLIN-S analysis, predict lower spectral accelerations than the generic soil equation. On one hand, the different site response analyses do not result in considerably different hazard curves, thus making the choice of an appropriate site response analysis approach less critical for the hazard analysis of site NES. On the other hand, the inability of the generic equation to capture the soil effects suggests that in the case of deep clayey deposits, even if these are classified as class D, the performance of a site-specific analysis is important.

At 1.0s the clayey site was seen to experience a considerably larger amplification than the alluvial site due to resonance with the elastic site period and the more linear behaviour of clayey soils. However, the majority of analyses show that the sandy site has the higher hazard estimates (Fig. 18). The clayey site experiences a considerably larger reduction in the standard deviation compared to that of rock. Specifically, $\sigma_{\operatorname{lnSa}(f)}{ }^{s}$ for NES varies between about 0.35 and 0.42 (for a source-to-site distance of $15 \mathrm{~km}$ which corresponds to the dominant hazard scenario), while that of $\mathrm{SCH}$ varies between 0.5 and 0.75 for the different analyses. The significant differences between the hazard curves of the two sites are thus driven by the large differences in the standard deviation for the two soil conditions and not by the considerably higher amplification experienced by the clayey site, demonstrating the strong impact that sigma has on the hazard analysis results.

We repeated the PSHA calculations for another two locations, within 10km from Location 1 ( 5 and $25 \mathrm{~km}$ from the San Andreas Fault), as the differences in the spectral acceleration estimates among the various GMPEs were seen to vary considerably with distance. The resulting hazard curves for the spectral acceleration of variable periods (PGA, 0.2s and 1.0s) are shown in Fig. 19.

The results for the site located just 5km from the San Andreas Fault (Fig. 19a) show extensive differences from the hazard curves obtained for Location 1. The hazard is significantly increased together with the variability among the curves obtained using the different GMPEs. For example, at $2 \% \mathrm{PE}$ in 50 years the parameters now vary from 0.7 to $1.7 \mathrm{~g}$ for PGA and from 2.0 to $5.6 \mathrm{~g}$ for $S_{a}{ }^{s}(1.0 \mathrm{~s})$. Once again, a significant degree of the observed variability is associated with the hazard curves produced using the EQLIN-I and EQLIN-D amplification functions, particularly in the intermediate period range. At the same time, the analysis yields a rock PGA close to $1.5 \mathrm{~g}$ and rock acceleration at $0.2 \mathrm{~s}$ approaching $4 \mathrm{~g}$. Despite the wide range of accelerations considered for the performance of the site response analysis and the derivation of the amplification functions, such high values were not encountered in the dataset. This means that at this level of probability and at such close distances to the dominating source, the amplification function is extrapolated to levels for which there is no data to constrain it and thus care is needed in the interpretation and validity of results. Differences are considerably smaller for the site located $25 \mathrm{~km}$ from the San Andreas Fault (Fig. 19b). In this case, the various GMPEs converge to more similar hazard estimates, with EQLIN-I in particular producing a hazard curve much closer to the rest of the analyses, in contrast to Fig. 18. However, the variability among the hazard curves is still considerable at these source-tosite distances, especially in the short-period range.

\subsection{Location 2: LA Bulk Mail (N34.053 $\left.{ }^{\circ}, \mathrm{W}_{118.243^{\circ}}\right)$}

The second location under consideration, Los Angeles Bulk Mail, is surrounded by a number of faults, in contrast to the Lancaster site whose hazard is almost entirely influenced by the San Andreas Fault. The contribution of the large number of active faults surrounding the area leads to an increased hazard. The main contributions are driven by a group of faults at distances varying from about 5 to $30 \mathrm{~km}$ and maximum magnitudes from about 6.0 to 7.0 , while the contribution of the San Andreas Fault becomes evident only at longer periods.

The hazard curves for the sandy soil conditions in Fig. 20 verify the increased hazard for the Bulk Mail location as PGA ranges from 0.45 to $0.92 \mathrm{~g}$ for a $10 \%$ PE in 50 years, while for the same 
exceedance level $S_{a}{ }^{s}(1.0 s)$ varies between 0.9 and $1.35 \mathrm{~g}$. In Section 3 it was clearly observed that the differences among the GMPEs increased significantly with increasing magnitude (both in the median and standard deviation). Given the lower magnitude of the dominant hazard scenario, one would expect smaller variability among the hazard curves predicted using the different equations. Nevertheless, the dominant scenario at short periods is also characterised by a very small source-tosite distance, less than $10 \mathrm{~km}$, which drives up the variability in the hazard estimates.

\section{Conclusions}

This paper investigated the sensitivity of the Bazzurro and Cornell [1] methodology, for the transformation of a rock ground-motion prediction equation to a site-specific one, for two class D sites with distinct soil stratigraphies, to a number of different parameters. Nonlinear regression was performed for the estimation of the median amplification function and its standard deviation, following the performance of multiple site response analyses, using different methods of analysis and model parameters in Papaspiliou et al. [6].

The differences between the amplification functions derived from nonlinear analyses and those derived from the equivalent linear analyses were mostly pronounced in the short-period range. The effects of the different modelling parameters for the nonlinear analysis influence $A F(f)$ across the entire acceleration range in the short-period range, while in the intermediate periods their effects are only noticeable for $S_{a}^{r}(f)>0.2 \mathrm{~g}$. The sandy site, due to its highly nonlinear behaviour and due to the presence of a low velocity layer at low confining pressures, was seen to be more sensitive to the employed site response analysis approach than the clayey site. Furthermore, the results of the equivalent linear analysis seem to suffer from larger scatter than those obtained from nonlinear methods of analysis. This implies that a larger number of records is needed for the robust estimation of the median $A F(f)$ and its standard deviation when the site response analysis is performed using equivalent linear methodologies.

The use of site-specific site response analysis and its proper incorporation in a rock GMPE was found to provide a significant reduction in the standard deviation, $\sigma_{\operatorname{lnSa}(f)}$, especially in comparison to estimates obtained with cruder approaches that do not consider the effect of soil nonlinearity on the standard deviation. The variability associated with the site response analysis for both sites and all methods of analysis was found to be smaller than the level often used in a number of recent ground-motion prediction equations, the effects of which on the total $\sigma_{\ln S a}{ }^{s}(f)$ were shown to be considerable. A reduction in the variability is achieved for the two class D sites, not only compared to the more traditional AS97 equation, but also compared to the NGA equations. This is in contrast to studies that have found site-specific analyses to be beneficial only in the case of soft soil sites (NEHRP E/Hlm deposits) or soft alluvial sites with an impedance contrast larger than a factor of $2[17,18]$.

The evaluation of the variability in the hazard estimates for a number of locations in California revealed significant differences in the final surface hazard curves. These differences become more pronounced with decreasing source-to-site distances. The nonlinear site response analysis was found to provide consistently more stable estimates of the soil behaviour, avoiding issues associated with the convergence problems in the equivalent linear methodology, which significantly influence the hazard analysis results, particularly in the intermediate period range. The above shortcoming of the equivalent linear analysis makes it unsuitable for the estimation of the site amplification for highly nonlinear alluvial sites and high levels of shaking intensity. Moreover, it is imperative for the site response analysis to be performed using records that span a wide enough range of rock accelerations, as the extrapolation of the amplification function to higher intensities can lead to severe problems. As expected, the influence of sigma on the results of the PSHA is dominant in most cases. A great proportion of the differences observed among the hazard curves were driven by the differences in the standard deviations of the corresponding ground-motion prediction equations, especially at lower probabilities of exceedance. Following the investigation of the sensitivity of ground response estimates to a number of parameters in Papaspiliou et al. [6] and 
the examination of their impact on the seismic hazard analysis presented herein, recommendations towards the performance of a site-specific site response analysis and its incorporation in PSHA are summarised in Fig. 21.

\section{References}

[1] P. Bazzurro, C.A. Cornell, Nonlinear Soil-Site Effects in Probabilistic Seismic-Hazard Analysis, Bulletin of the Seismological Society of America, 94 (2004) 2110-2123.

[2] C.A. Goulet, J.P. Stewart, Pitfalls of Deterministic Application of Nonlinear Site Factors in Probabilistic Assessment of Ground Motions, Earthquake Spectra, 25 (2009) 541-555.

[3] C.-C.P. Tsai, Probabilistic Seismic Hazard Analysis Considering Nonlinear Site Effect, Bulletin of the Seismological Society of America, 90 (2000) 66-72.

[4] P. Bazzurro, C.A. Cornell, Ground-Motion Amplification in Nonlinear Soil Sites with Uncertain Properties, Bulletin of the Seismological Society of America, 94 (2004) 2090-2109.

[5] X.S. Li, Z.L. Wang, C.K. Shen, SUMDES: a nonlinear procedure for response analysis of horizontallylayered sites subjected to multi-directional earthquake loading, Dept. of Civil Engineering, Univ. of California, Davis, 1992.

[6] M. Papaspiliou, S. Kontoe, J.J. Bommer, An Exploration of Incorporating Site Response in to PSHA Part I: Issues related to site response analysis methods, Journal of Soil Dynamics and Earthquake Engineering, Submitted (2010).

[7] N.A. Abrahamson, W.J. Silva, Empirical Response Spectra Attenuation Relations for Shallow Crustal Earthquakes, Seismological Research Letters, 68 (1997) 94-127.

[8] K.W. Campbell, Y. Bozorgnia, NGA Ground Motion Model for the Geometric Mean Horizontal Component of PGA, PGV, PGD and 5\% Damped Linear Elastic Response Spectra for Periods Ranging from 0.01 to $10 \mathrm{~s}$, Earthquake Spectra, 24 (2008) 139-171.

[9] N. Abrahamson, W. Silva, Summary of the Abrahamson \& Silva NGA Ground-Motion Relations, Earthquake Spectra, 24 (2008) 67-97.

[10] EC8, Eurocode 8: design of structures for earthquake resistance - Part 1: general rules, seismic actions and rules for buildings, European Norm., European Committee for Standardisation, 2004.

[11] B.S.S.C. (BSSC), NEHRP Recommended Provisions for Seismic Regulations for New Buildings and Other Structures, Part 1: Provisions and Part 2: Commentary, Federal Emenergency Management Agency, Washington D.C., 2001.

[12] G.R. Toro, N.A. Abrahamson, J.F. Schndeider, Model of strong ground motions from earthquakes in central and eastern North America: best estimates and uncertainty, Seismological Research Letters, 68 (1997) 41-57.

[13] E.H. Field, T.H. Jordan, C.A. Cornell, OpenSHA: A Developing Community-Modeling Environment for Seismic Hazard Analysis, Seismological Research Letters, 74 (2003) 406-419.

[14] M. Power, B. Chiou, N. Abrahamson, Y. Bozorgnia, T. Shantz, C. Roblee, An Overview of the NGA Project, Earthquake Spectra, 24 (2008) 3-21.

[15] A.D. Frankel, M.D. Petersen, C.S. Mueller, K.M. Haller, R.L. Wheeler, E.V. Leyendecker, R.L. Wesson, S.C. Harmsen, C.H. Cramer, D.M. Perkins, K.S. Rukstales, Documentation for the 2002 Update of the National Seismic Hazard Maps, Open-File Report 2002-420, USGS, 2002.

[16] P. Bazzurro, C.A. Cornell, Disaggregation of Seismic Hazard, Bulletin of the Seismological Society of America, 89 (1999) 501-520.

[17] M.B. Baturay, J.P. Stewart, Uncertainty and Bias in Ground-Motion Estimates from Ground Response Analyses, Bulletin of the Seismological Society of America, 93 (2003) 2025-2042.

[18] J.P. Stewart, Y. Choi, M.B. Baturay, A.H. Liu, Models for Incorporating Site Effects in Probabilistic Seismic Hazard Analyses, 13th World Conference on Earthquake Engineering, Vancouver, Canada, 2004. 


\section{Figure Captions}

Fig. 1: Plots of amplification factors following NON-D_FR2 analysis together with the regression results (median $+/$ - one standard deviation amplification function and 95\% confidence intervals).

Fig. 2: Median amplification functions for Sylmar County Hospital ( $\mathrm{SCH})$.

Fig. 3: Results of the site response analysis for EQLIN-S, EQLIN-I and EQLIN-D for spectral periods $\mathrm{T}=0.8$ and $1.0 \mathrm{~s}$.

Fig. 4: Median amplification functions for Nesher Site (NES).

Fig. 5: Variation of the standard deviation, $\sigma_{\ln A F(f)}$, for different site response analyses and periods for (a) $\mathrm{SCH}$ and (b) NES.

Fig. 6: (a) Regression for site $\mathrm{SCH}$ and $\mathrm{T}=0.2 \mathrm{~s}$; (b) Variation of $\mathrm{AF}$ residuals with respect to $S_{a}{ }^{r}(0.2 s)$.

Fig. 7: Comparison of amplification functions for sites SCH (solid lines) and NES (dashed lines) for spectral periods equal to 1.0 and 1.5 .

Fig. 8: Comparison of site-specific median amplification functions (solid lines: SCH, dashed lines: NES) with EC8 and NEHRP amplification factors for T=0.2 and 1.0s.

Fig. 9: Median surface spectral acceleration for site SCH estimated for a magnitude 6.0 (dashed lines) and a magnitude 8.0 (solid lines) event.

Fig. 10: Median surface spectral acceleration for site NES estimated for a magnitude 6.0 (dashed lines) and a magnitude 8.0 (solid lines) event.

Fig. 11: Variation of the standard deviation, $\sigma_{\operatorname{lnSa}(f)}^{s}$, for site $\mathrm{SCH}$ and (a) a magnitude 6.0 event, (b) a magnitude 8.0 event.

Fig. 12: Variation of the standard deviation, $\sigma_{\operatorname{lnSa} a_{(f)}}$, for site NES for (a) a magnitude 6.0 event and (b) a magnitude 8.0 event.

Fig. 13: Variation of the standard deviation for (a) the Sylmar County Hospital site and (b) the Nesher site for a $\mathrm{M}=7$ event at $\mathrm{T}=0.2 \mathrm{~s}$.

Fig. 14: Variation of the standard deviation (a) for the $\mathrm{SCH}$ site and (b) the NES site for $\mathrm{T}=0.2 \mathrm{~s}, \mathrm{a} M=7$ event and $\sigma_{\ln A F(f)}$ is fixed to 0.3 (ln units).

Fig. 15: Surface hazard curves obtained using the results of different site response analysis approaches for site $\mathrm{SCH}$, located at Lancaster site.

Fig. 16: Disaggregation results for PGA at the (a) $10 \%$ probability of exceedance in 50 years level and (b) $2 \%$ probability of exceedance in 50 years level.

Fig. 17: Surface hazard curves obtained using the results of different site response analysis approaches for a hypothetical clayey site (NES) located at Lancaster.

Fig. 18: Comparison of the hazard curves for the alluvial (solid lines) and clayey sites (dashed lines) for $\mathrm{T}=1.0 \mathrm{~s}$.

Fig. 19: Surface hazard curves obtained using the results of different site response analysis approaches for the alluvial site condition ( $\mathrm{SCH}$ ) (a) $5 \mathrm{~km}$ and (b) $25 \mathrm{~km}$ from the San Andreas Fault. 
Fig. 20: Surface hazard curves obtained using the results of different site response analysis approaches for a hypothetical alluvial site (SCH) located at L.A. Bulk Mail.

Fig. 21: Flow chart summarising the procedure towards the estimation of site effects and their incorporation in probabilistic seismic hazard analyses (PSHA). 


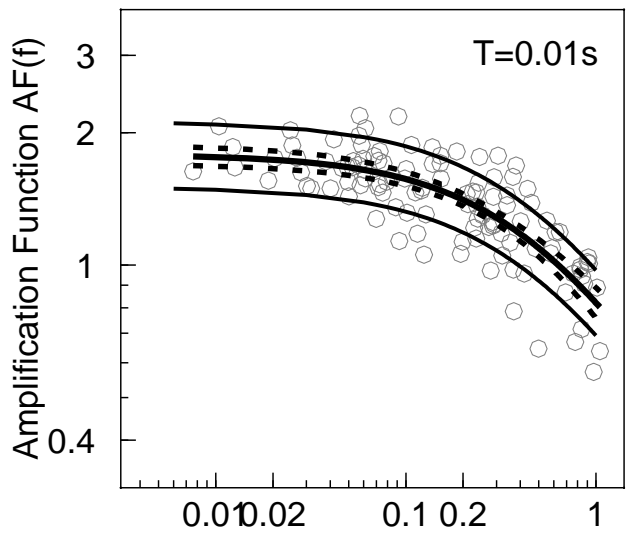

Rock Spectral Acceleration $S_{a}{ }^{r}$

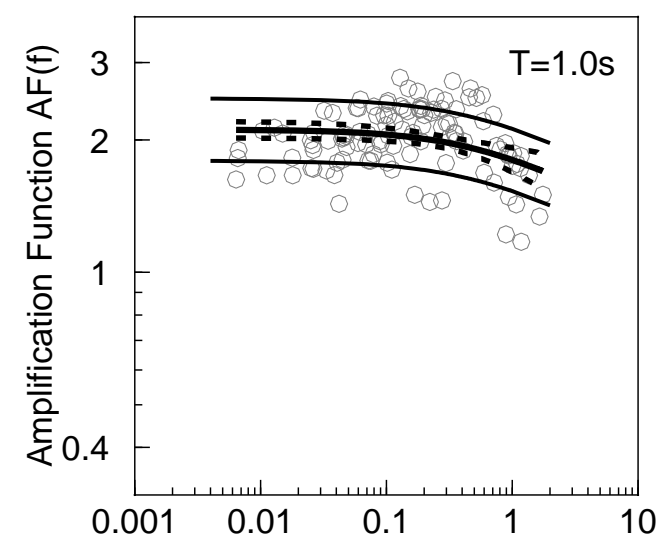

Rock Spectral Acceleration $S_{a}{ }^{r}$

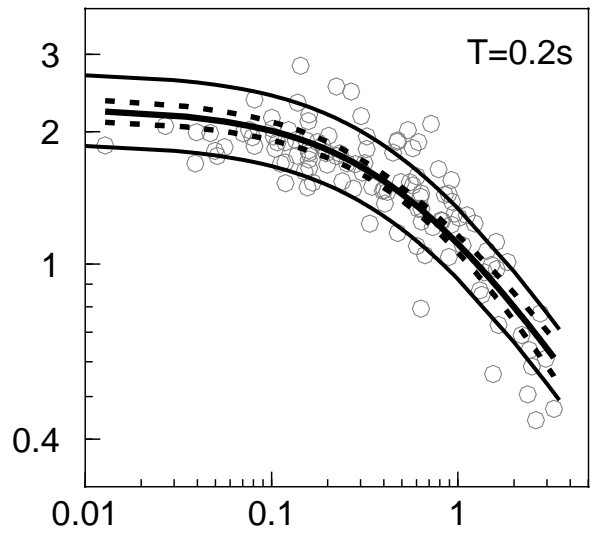

Rock Spectral Acceleration $\mathrm{S}_{\mathrm{a}}{ }^{\mathrm{r}}$

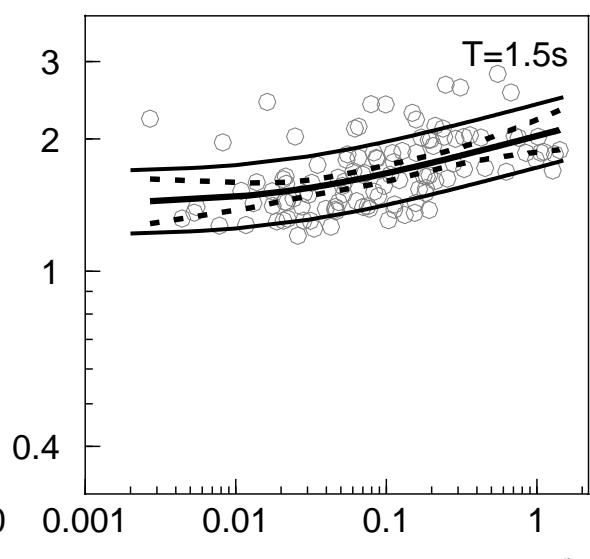

Rock Spectral Acceleration $\mathrm{S}_{\mathrm{a}}{ }^{\mathrm{r}}$

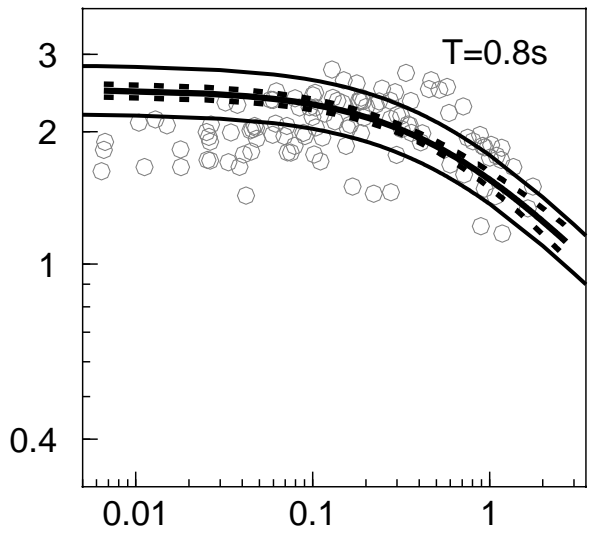

Rock Spectral Acceleration $\mathrm{S}_{\mathrm{a}}{ }^{\mathrm{r}}$

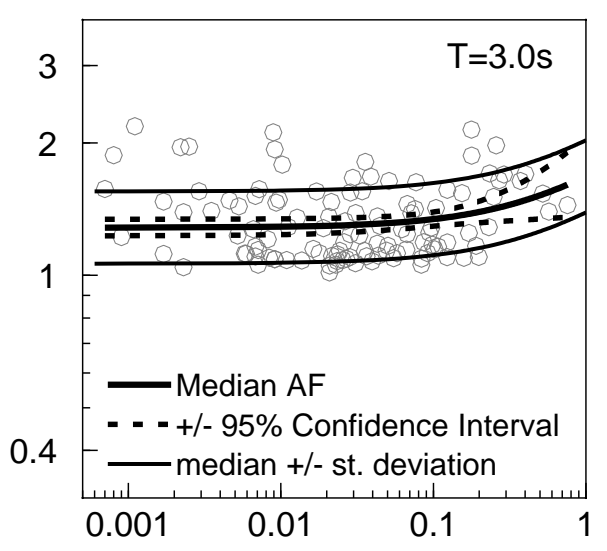

Rock Spectral Acceleration $S_{a}{ }^{r}$ 

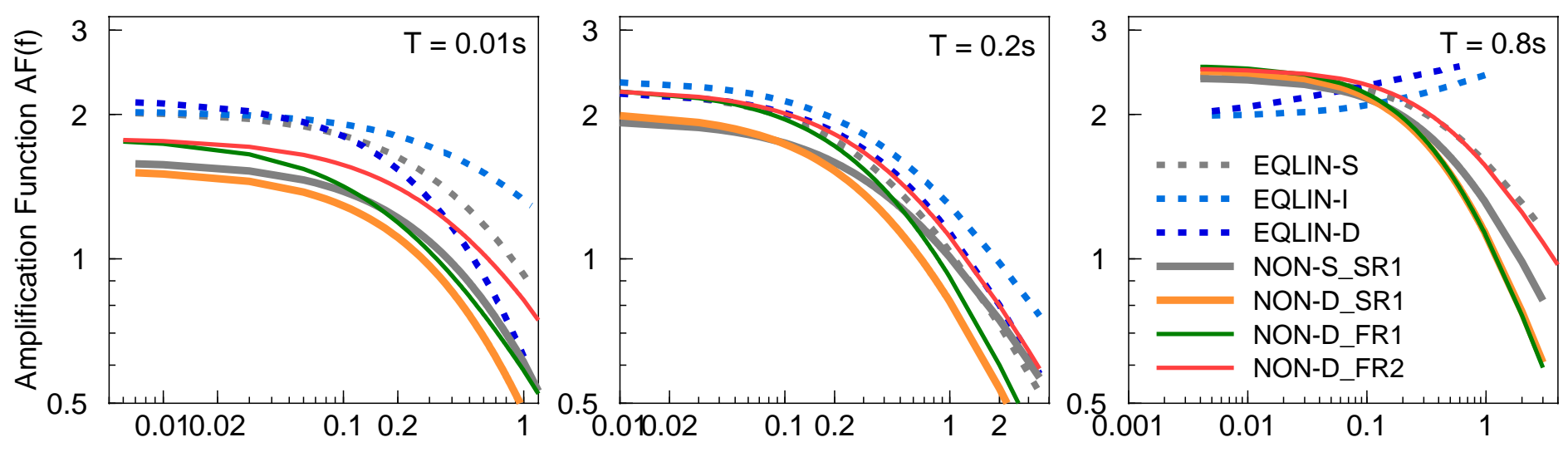

Rock Spectral Acceleration $S_{a}{ }^{r}(g) \quad$ Rock Spectral Acceleration $S_{a}{ }^{r}(g)$

Rock Spectral Acceleration $\mathrm{S}_{\mathrm{a}}{ }^{\mathrm{r}}(\mathrm{g})$
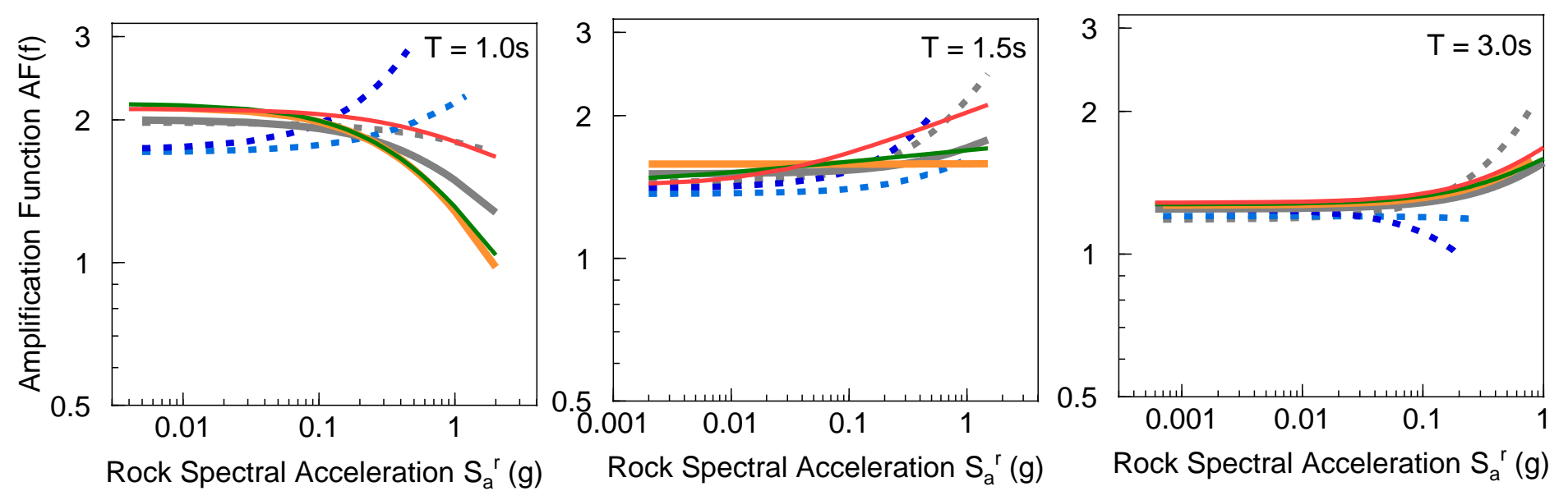
Figure 3
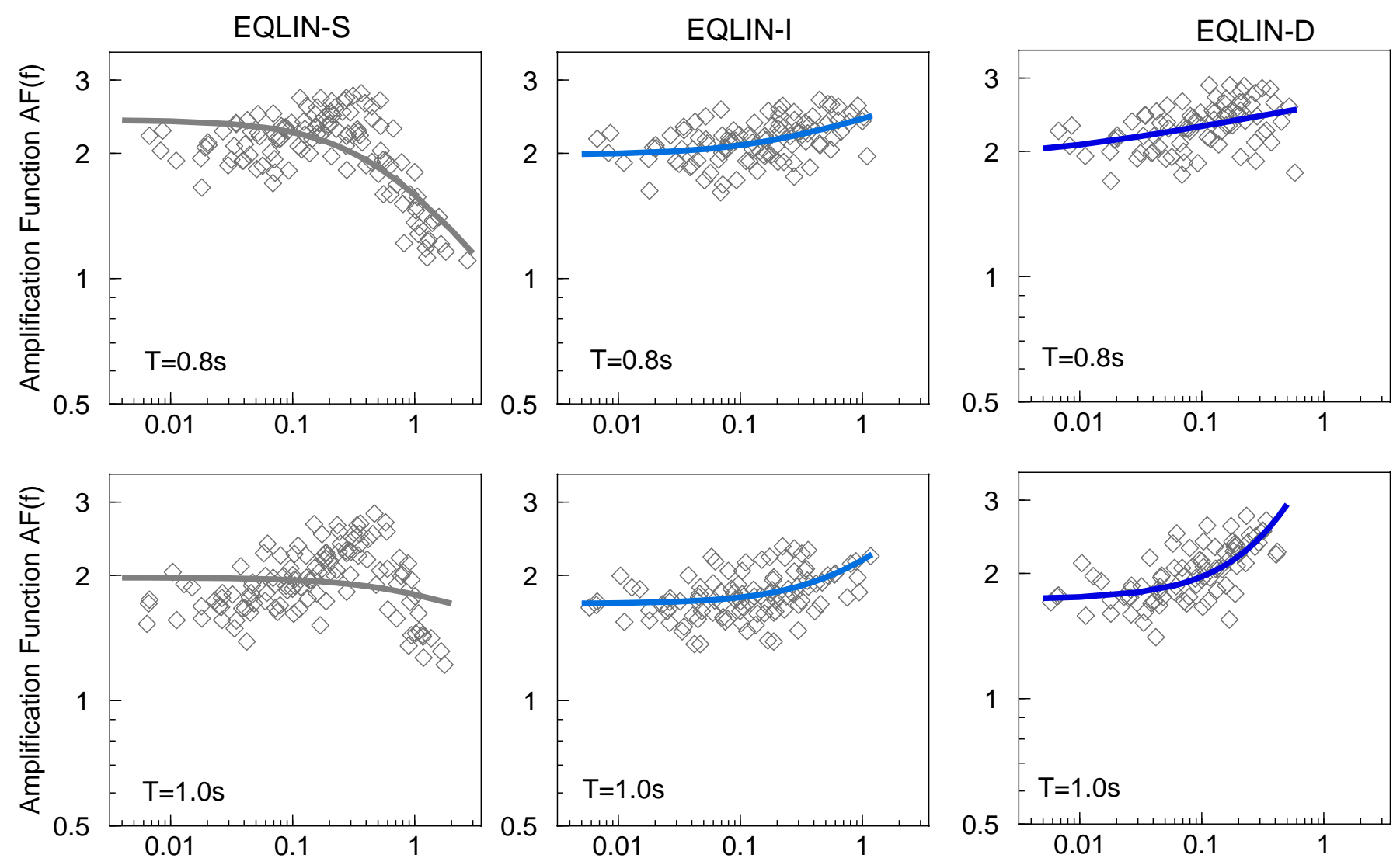

Rock Spectral Acceleration $S_{a}{ }^{r}(g)$

Rock Spectral Acceleration $S_{a}{ }^{r}(g)$

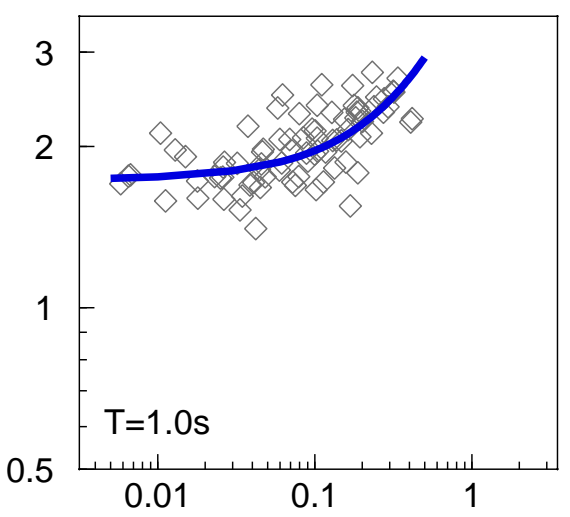

Rock Spectral Acceleration $\mathrm{S}_{\mathrm{a}}{ }^{\mathrm{r}}(\mathrm{g})$ 

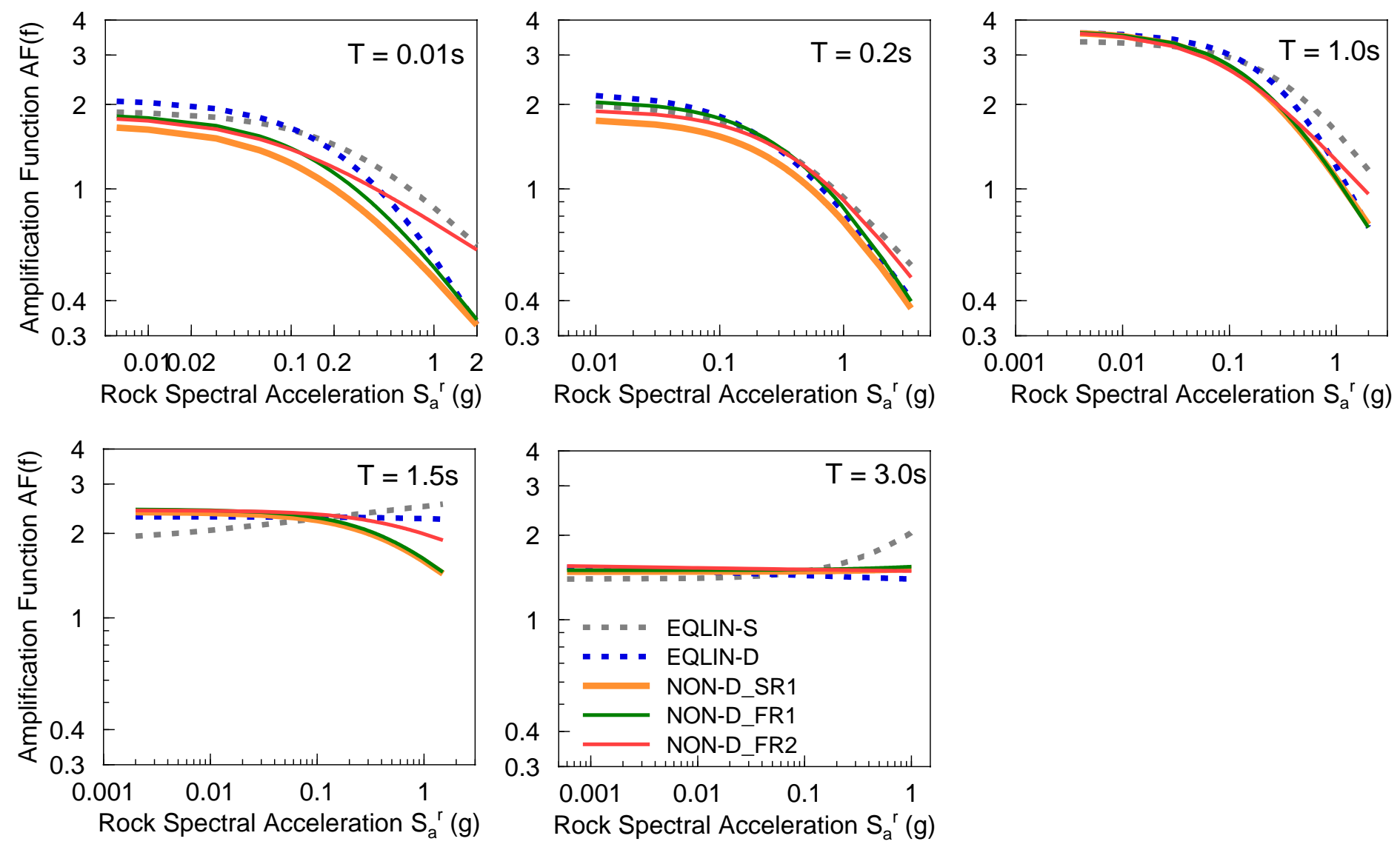
Figure 5
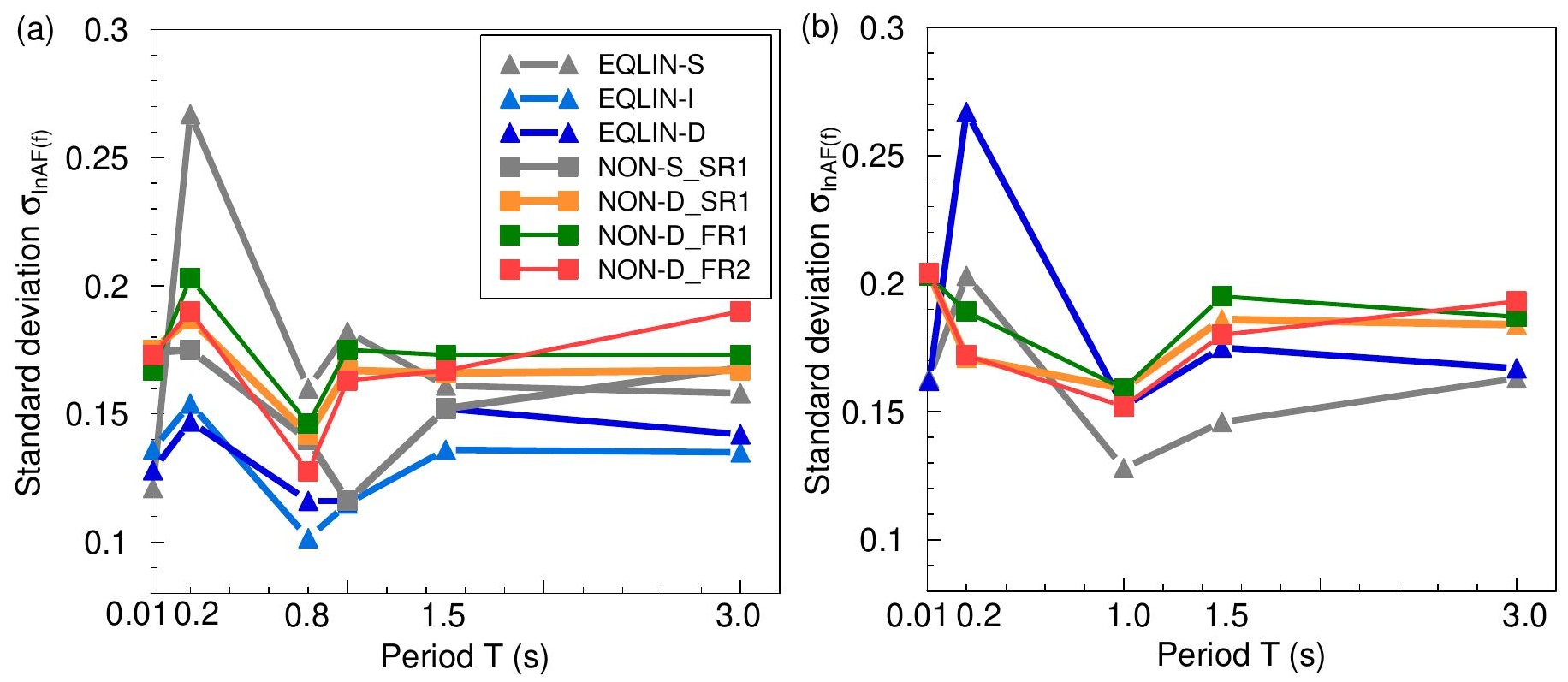
Figure 6
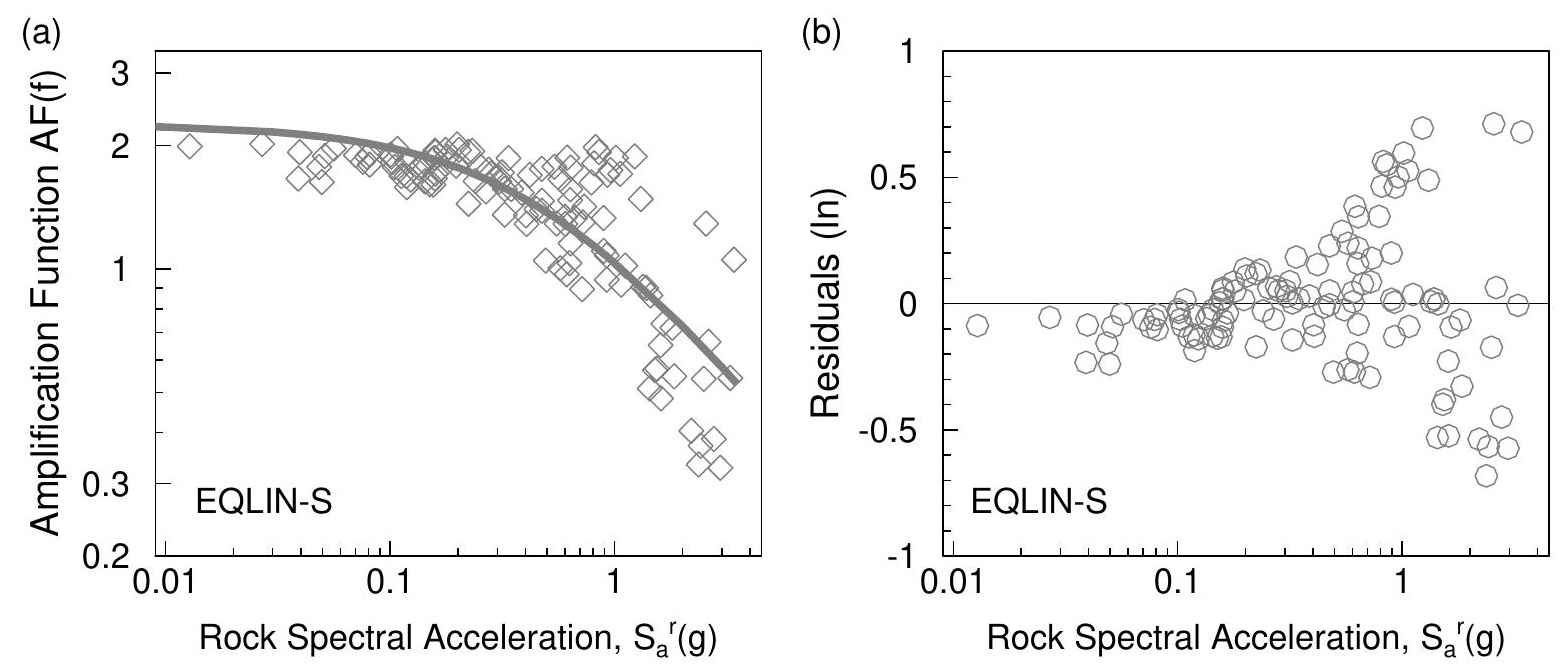
Figure 7
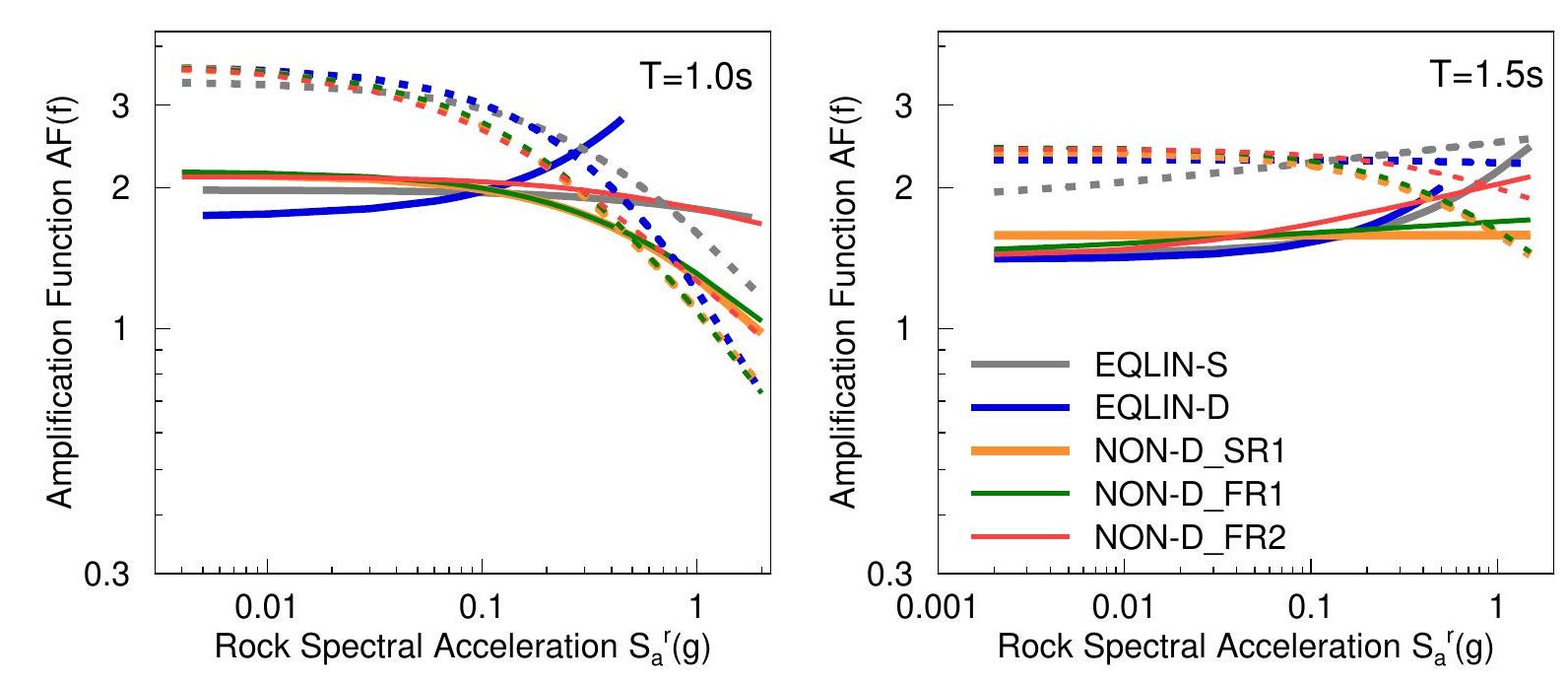

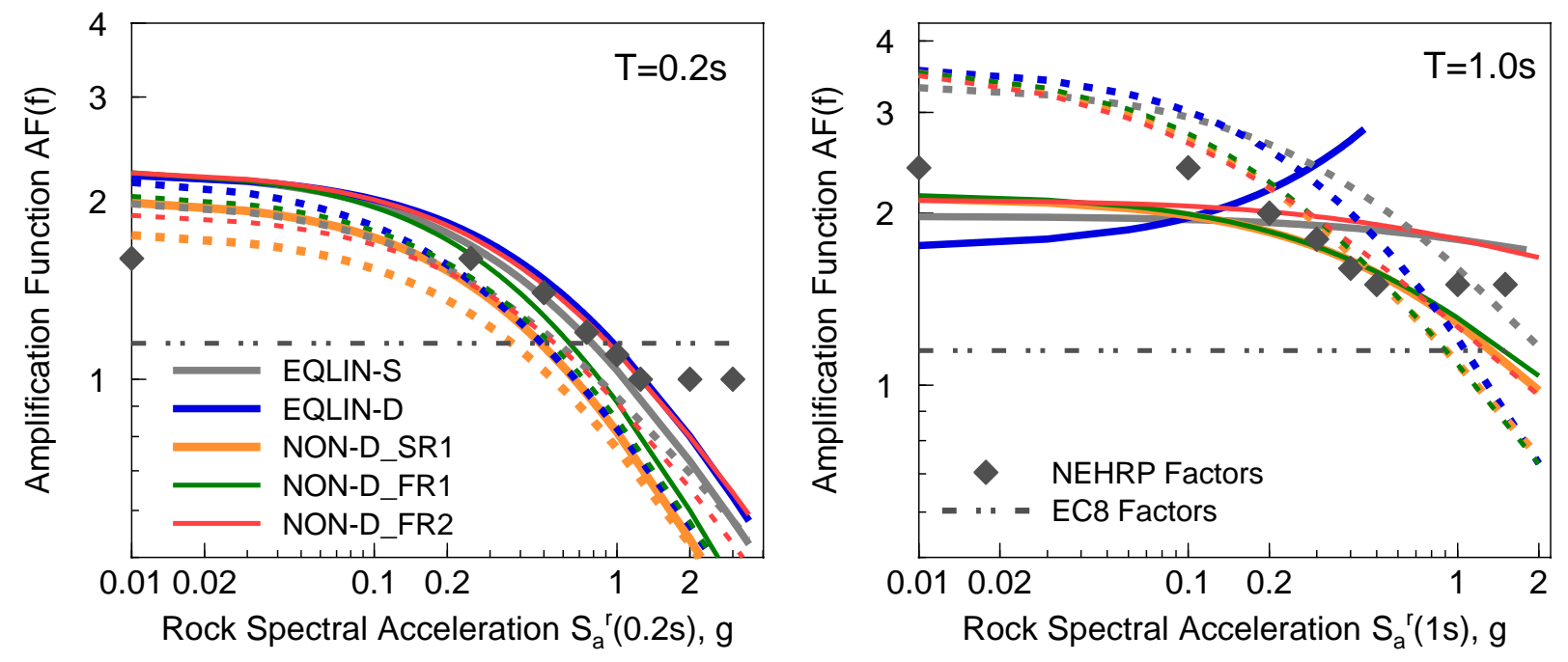

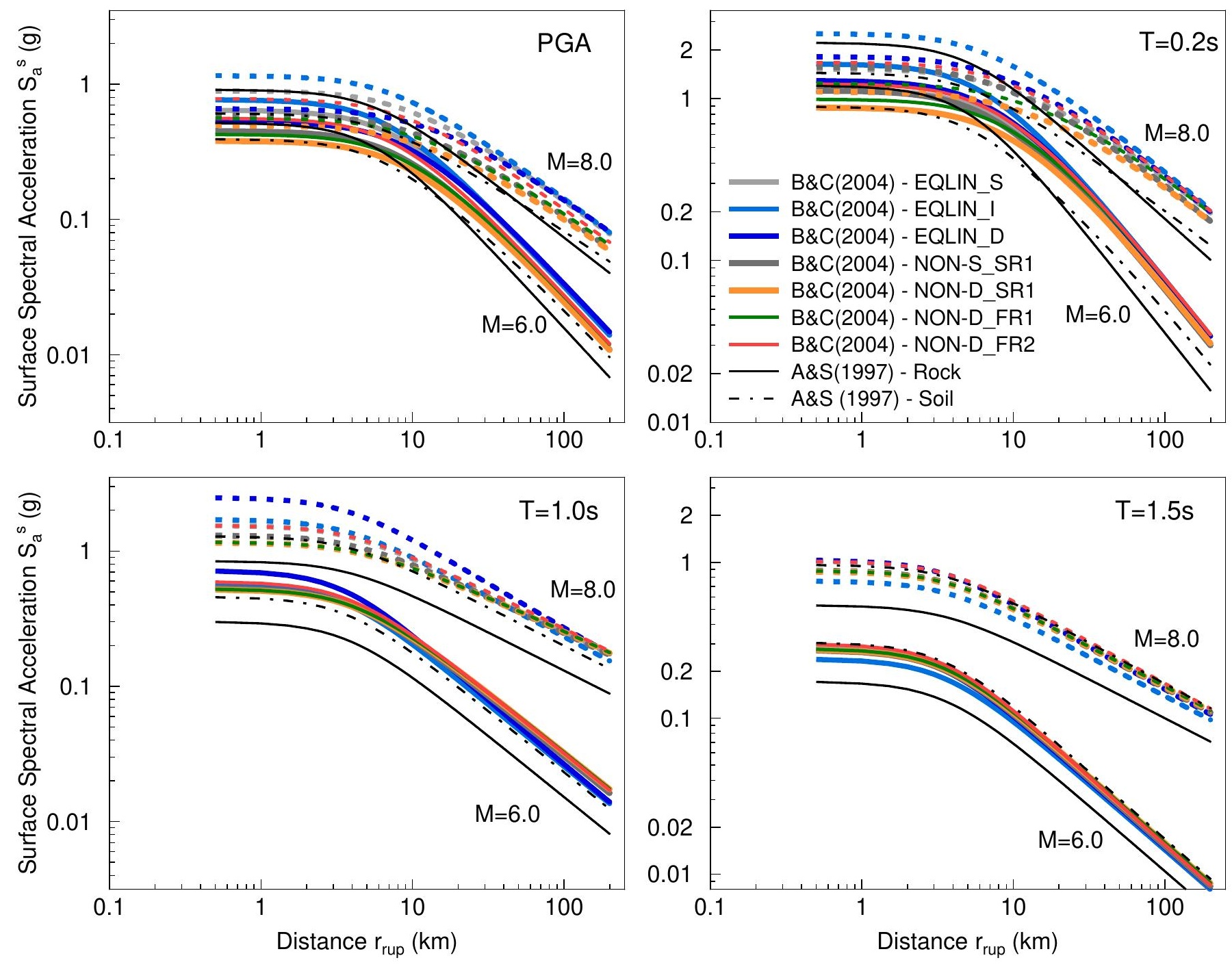

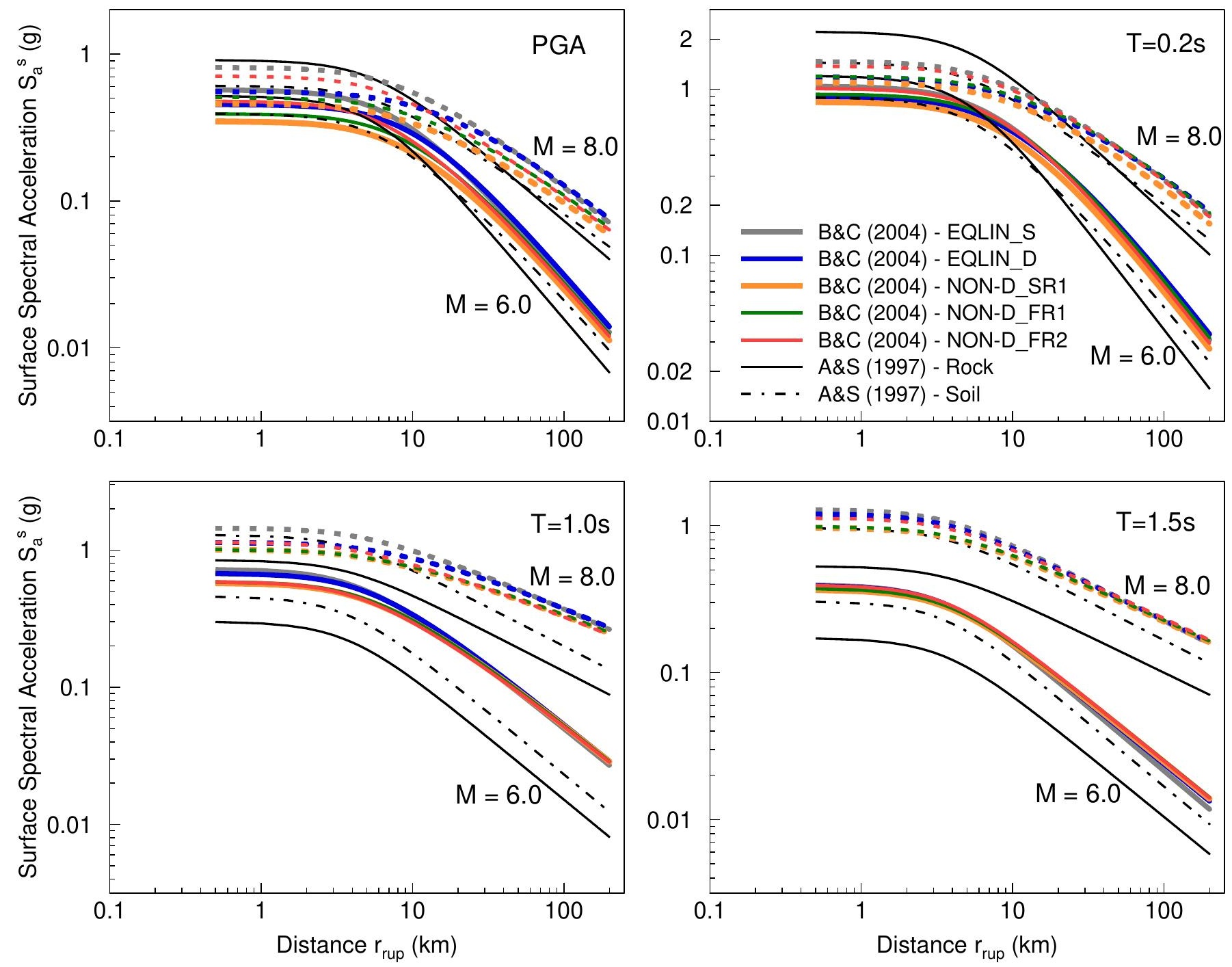
(a) $M=6.0$

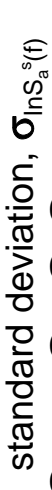

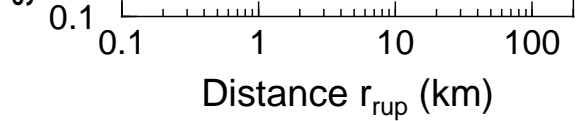

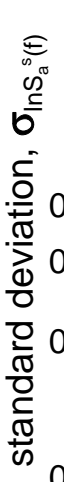$$
\text { ๘ }
$$

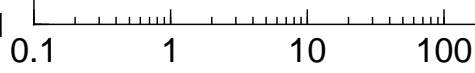

Distance $r_{\text {rup }}(\mathrm{km})$
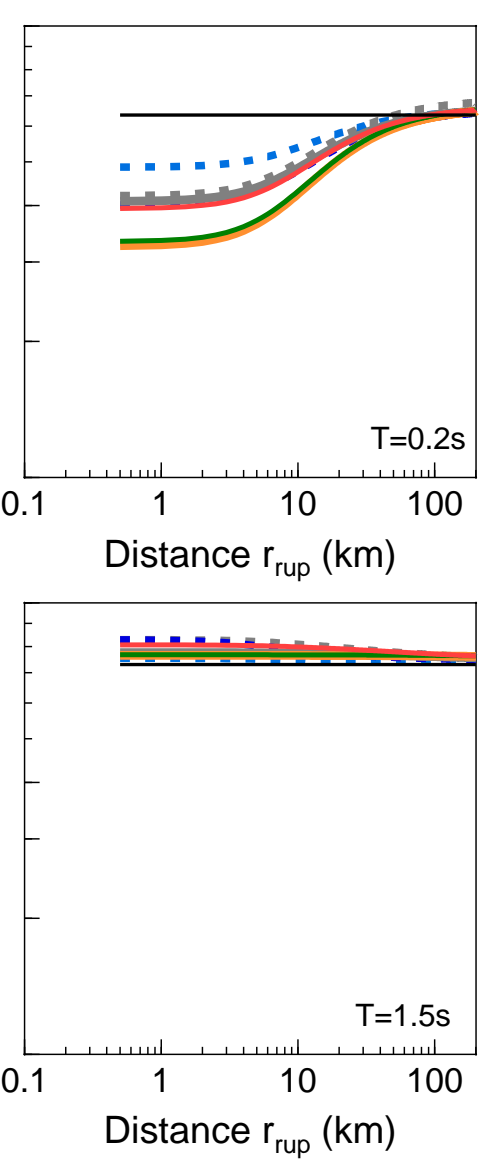

(b) $M=8.0$
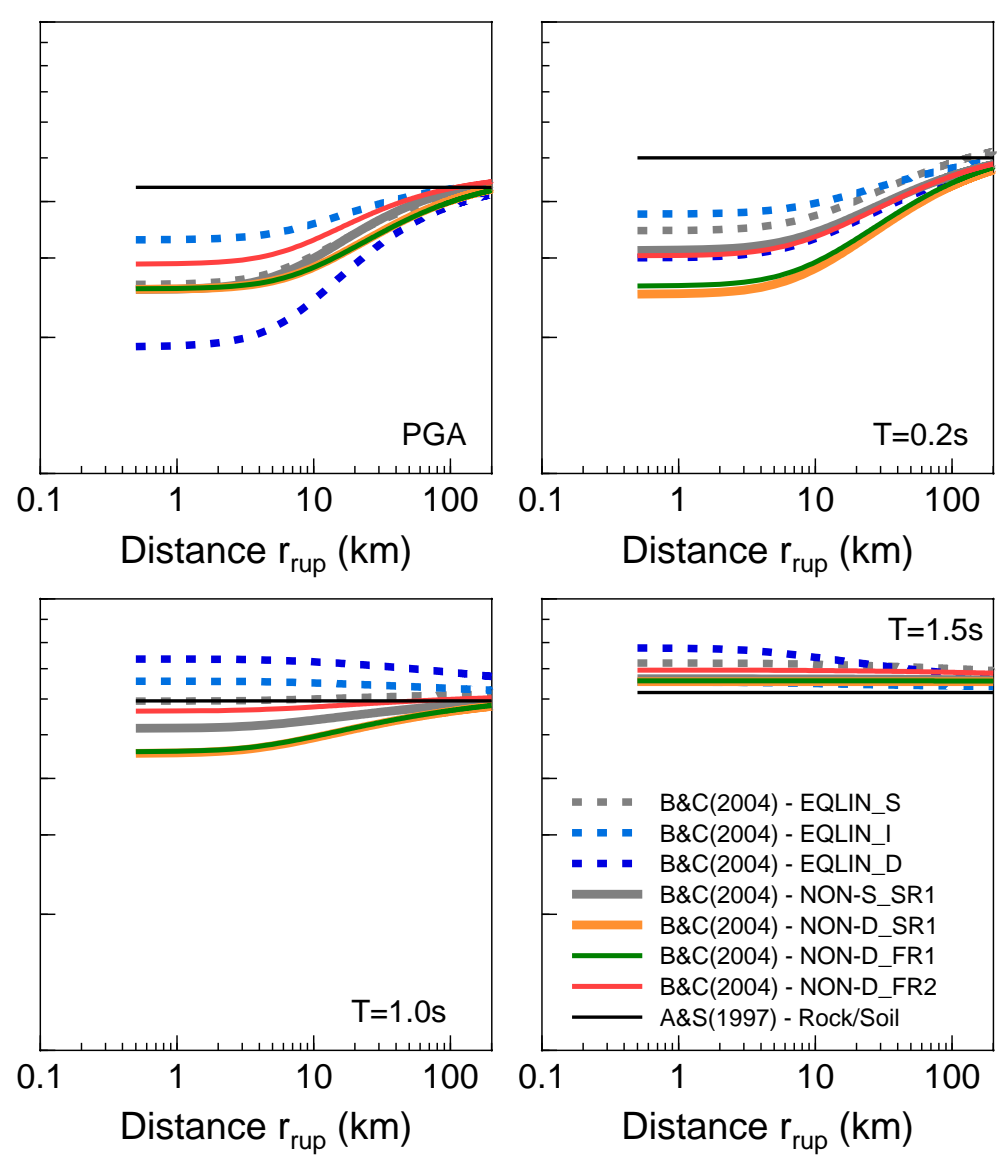
(a) $M=6.0$

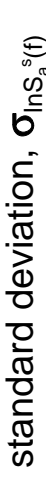

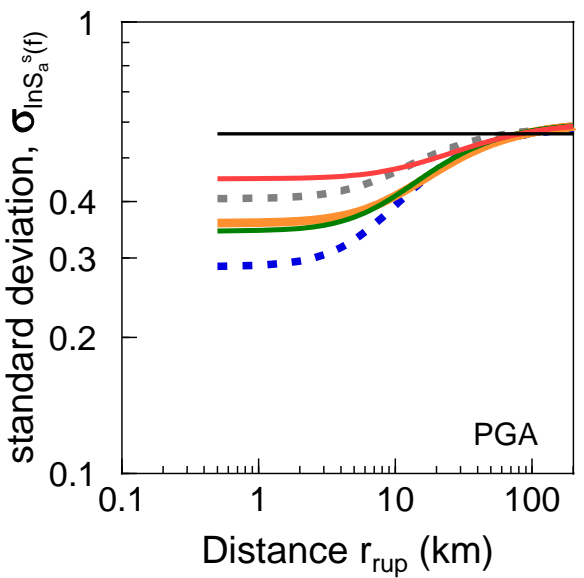

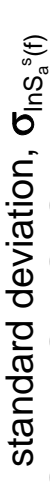
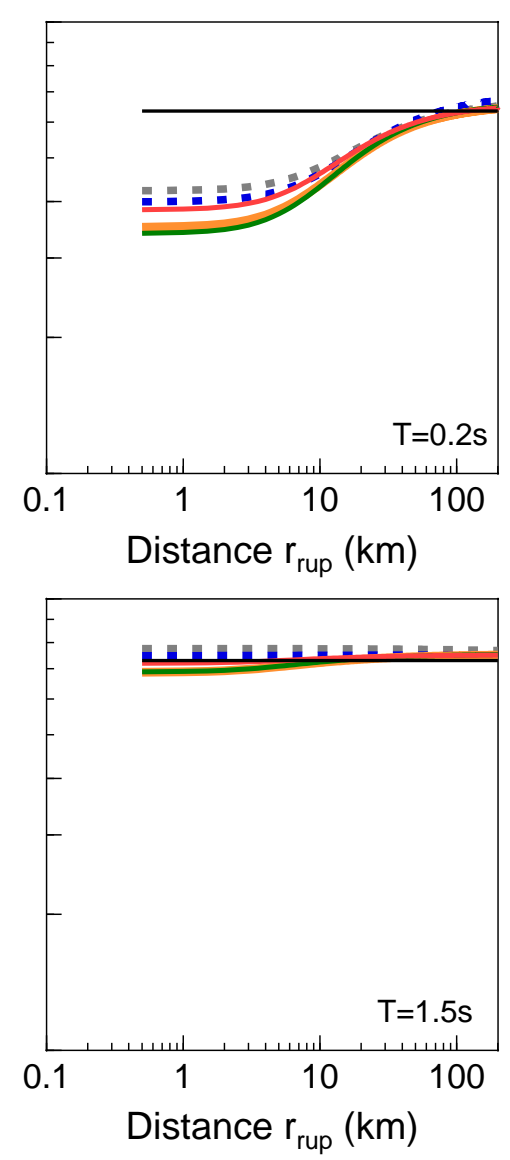

(b) $M=8.0$
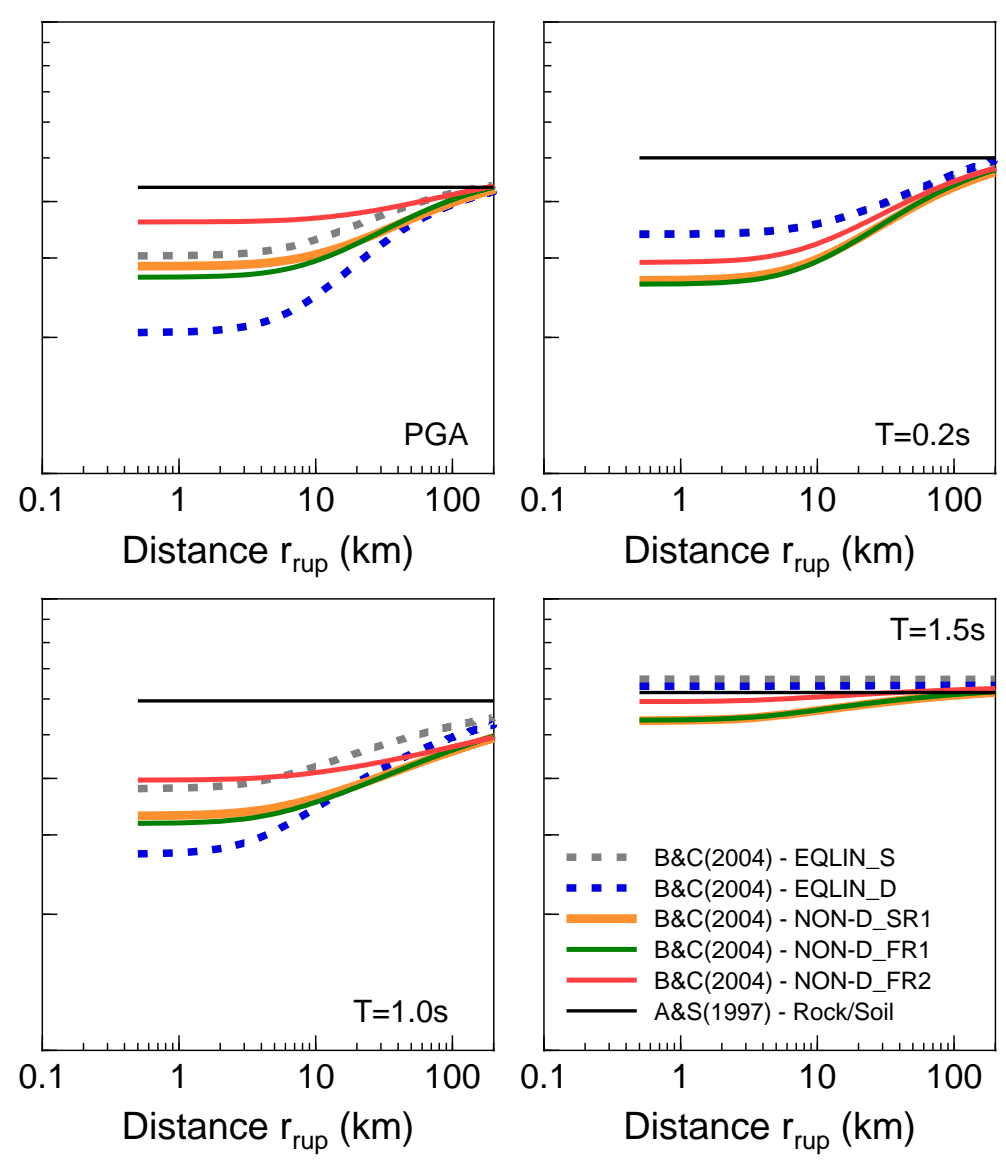

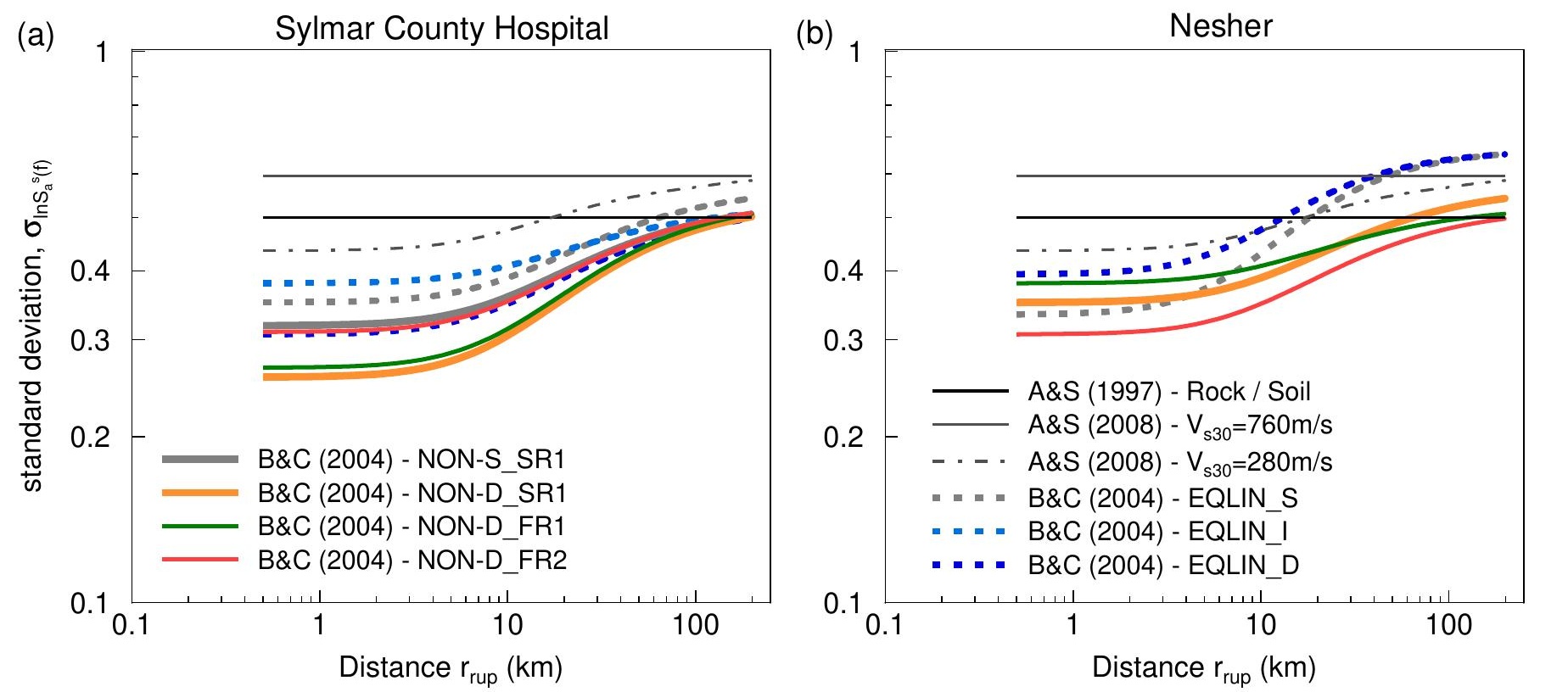

Figure 13

$-$

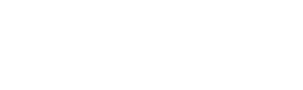

.

.

.
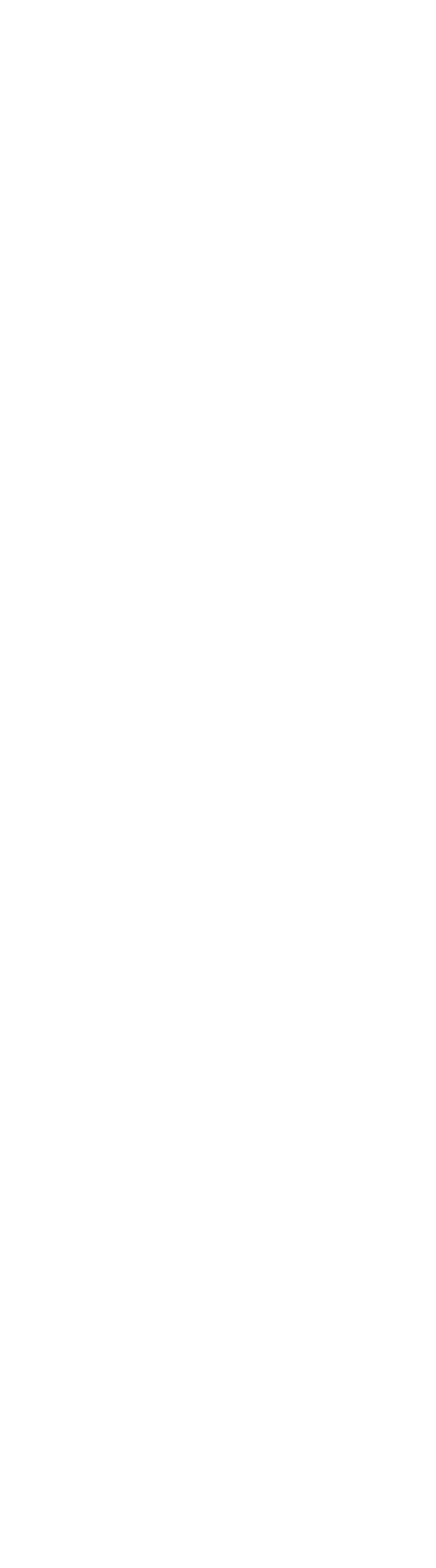

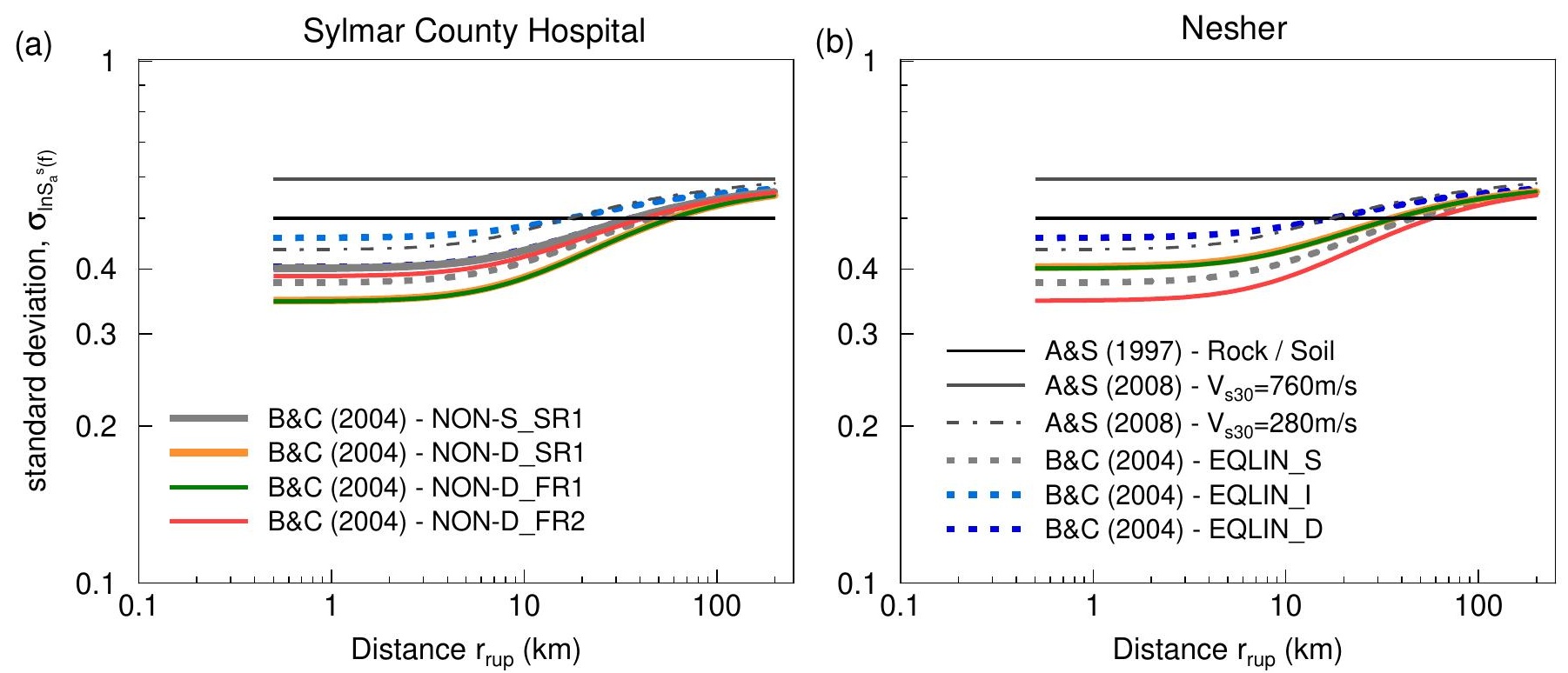

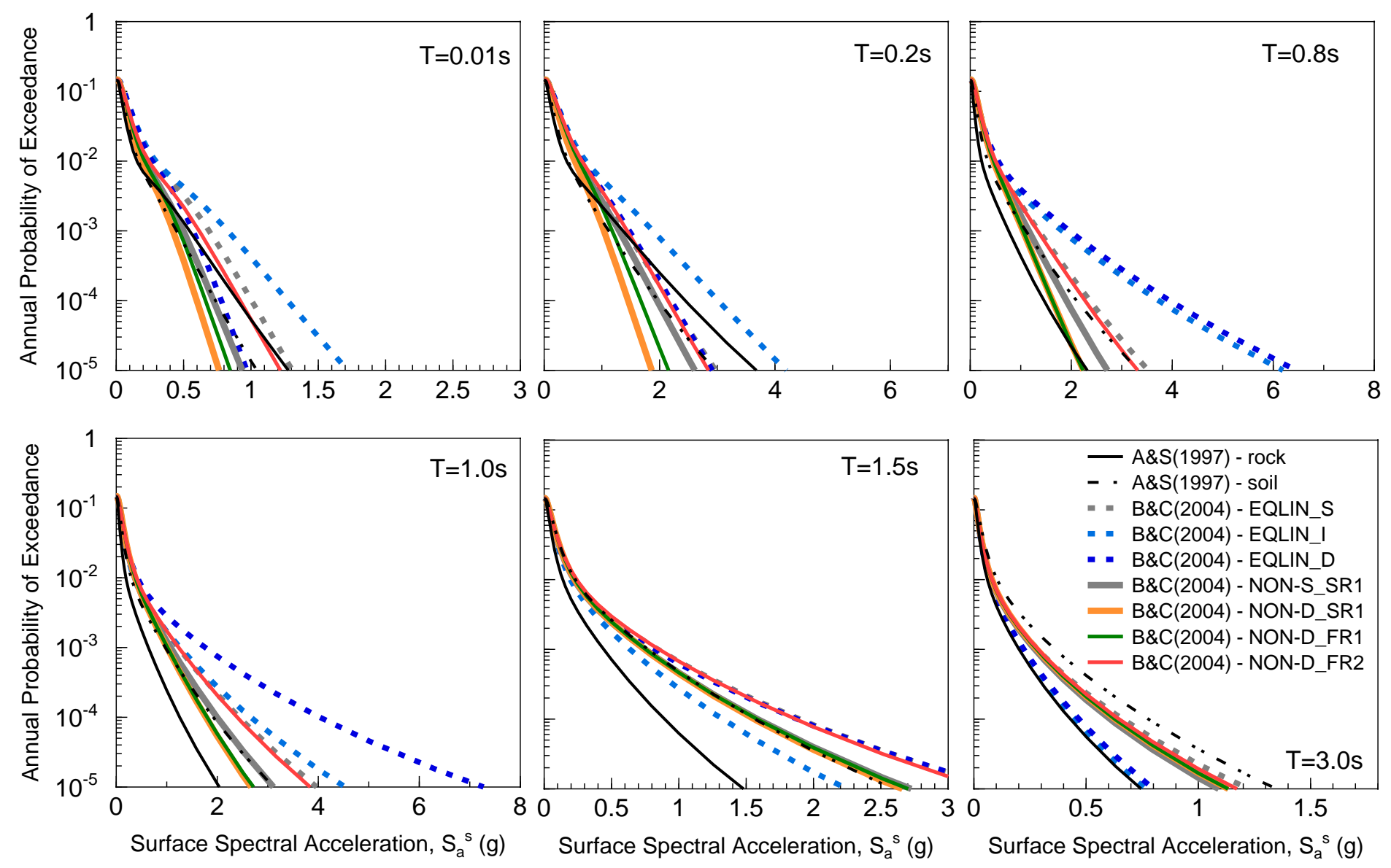
Click here to download high resolution image
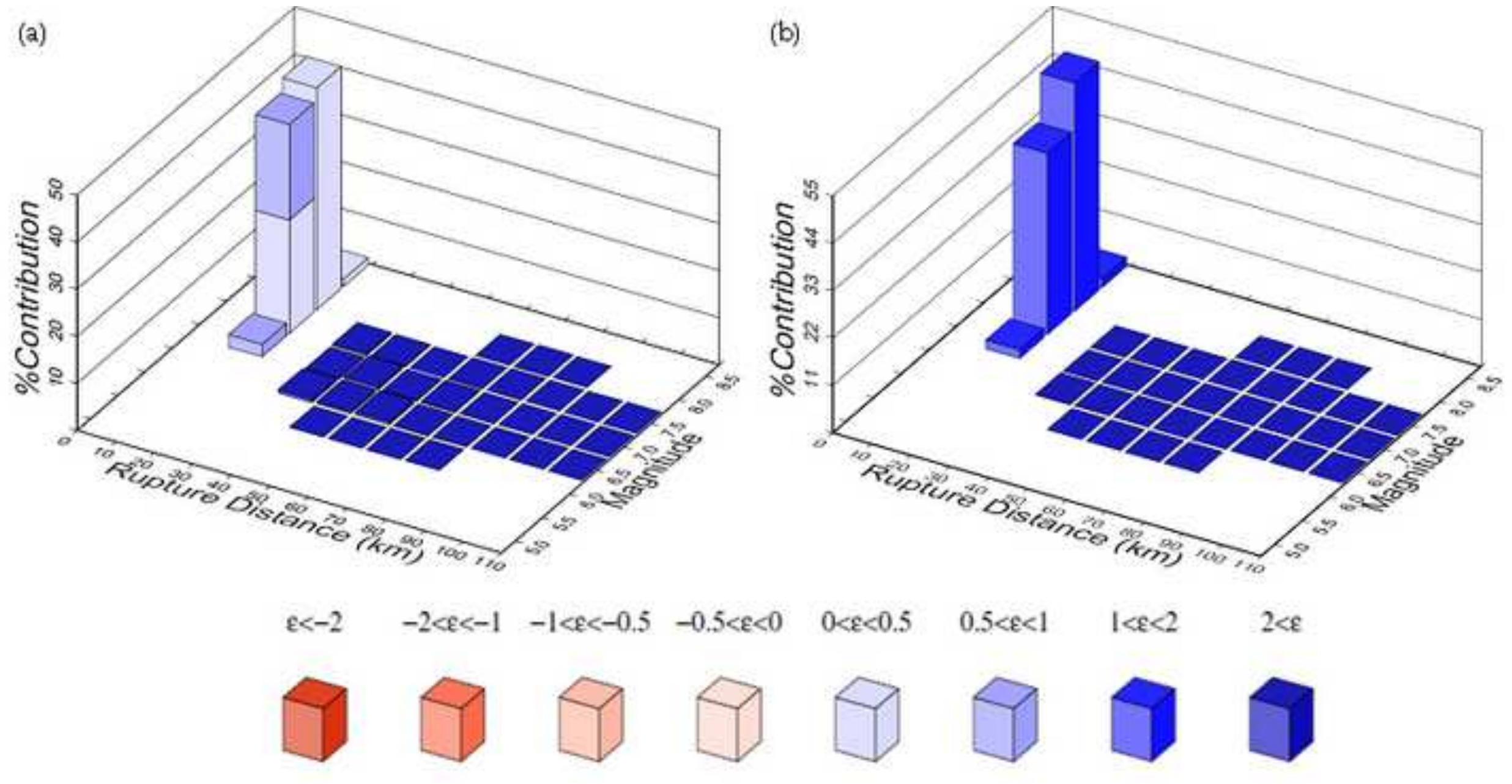

\section{Clck here to download high resolution image}

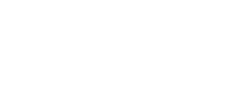



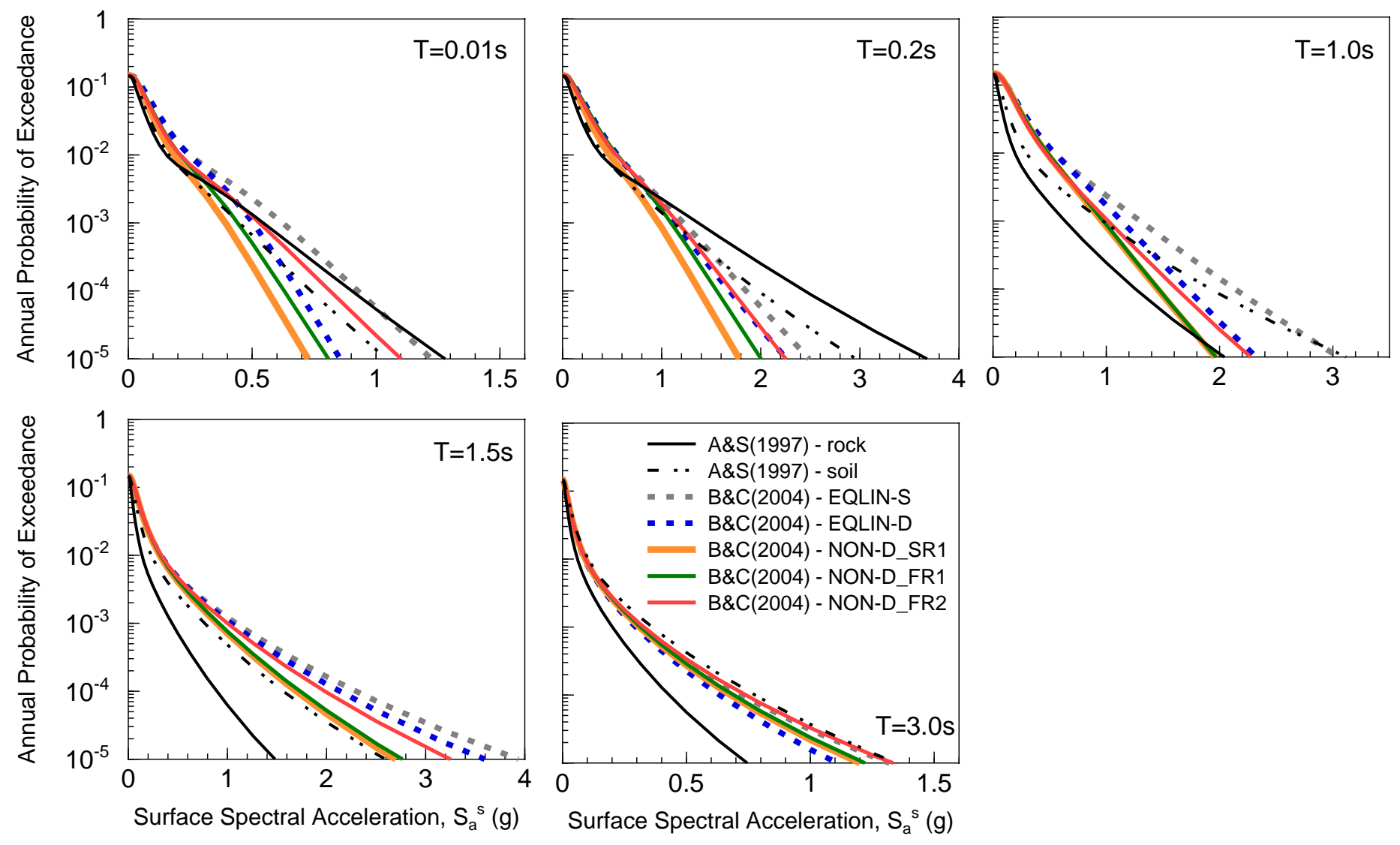
Figure 18

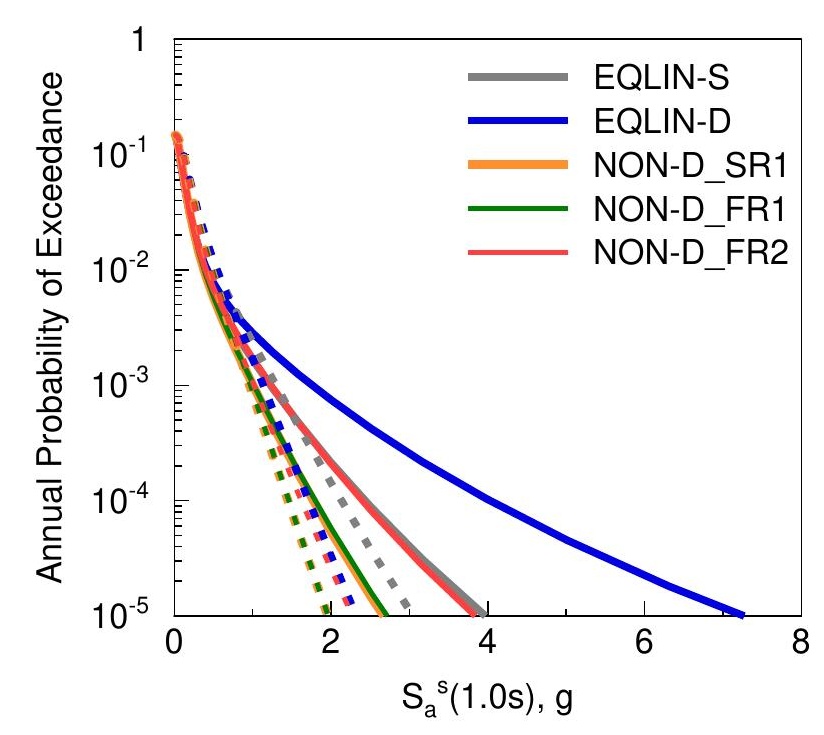

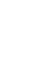
$S_{a}^{s}(1.0 s), g$ 
(a)

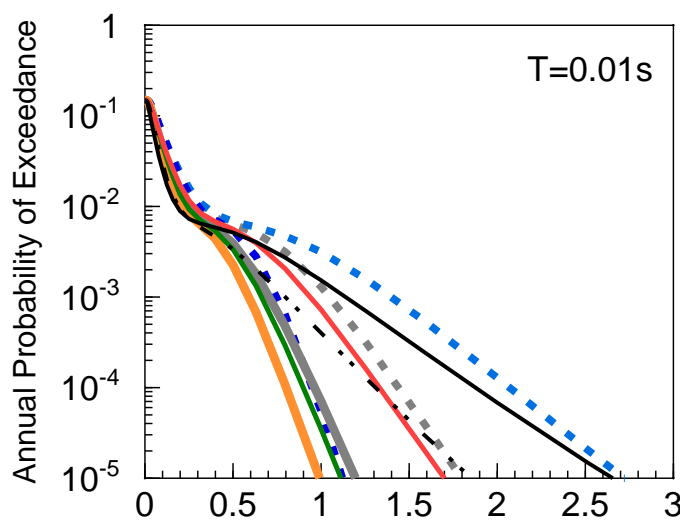

(b)

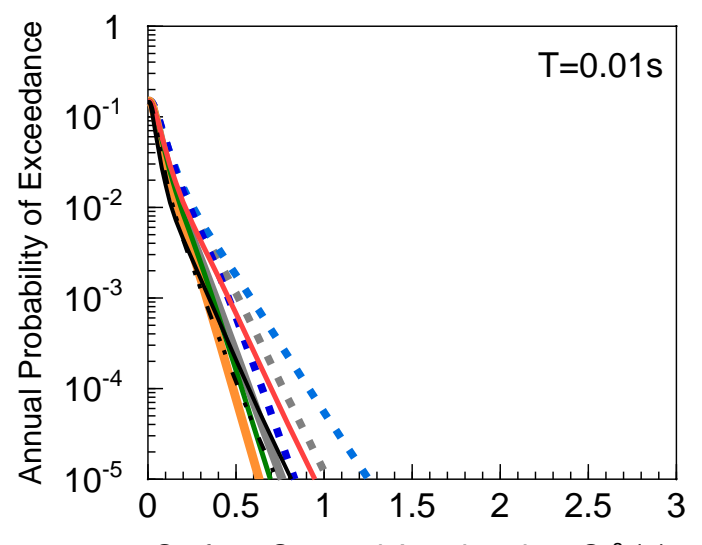

Surface Spectral Acceleration, $\mathrm{S}_{\mathrm{a}}{ }^{\mathrm{s}}(\mathrm{g})$
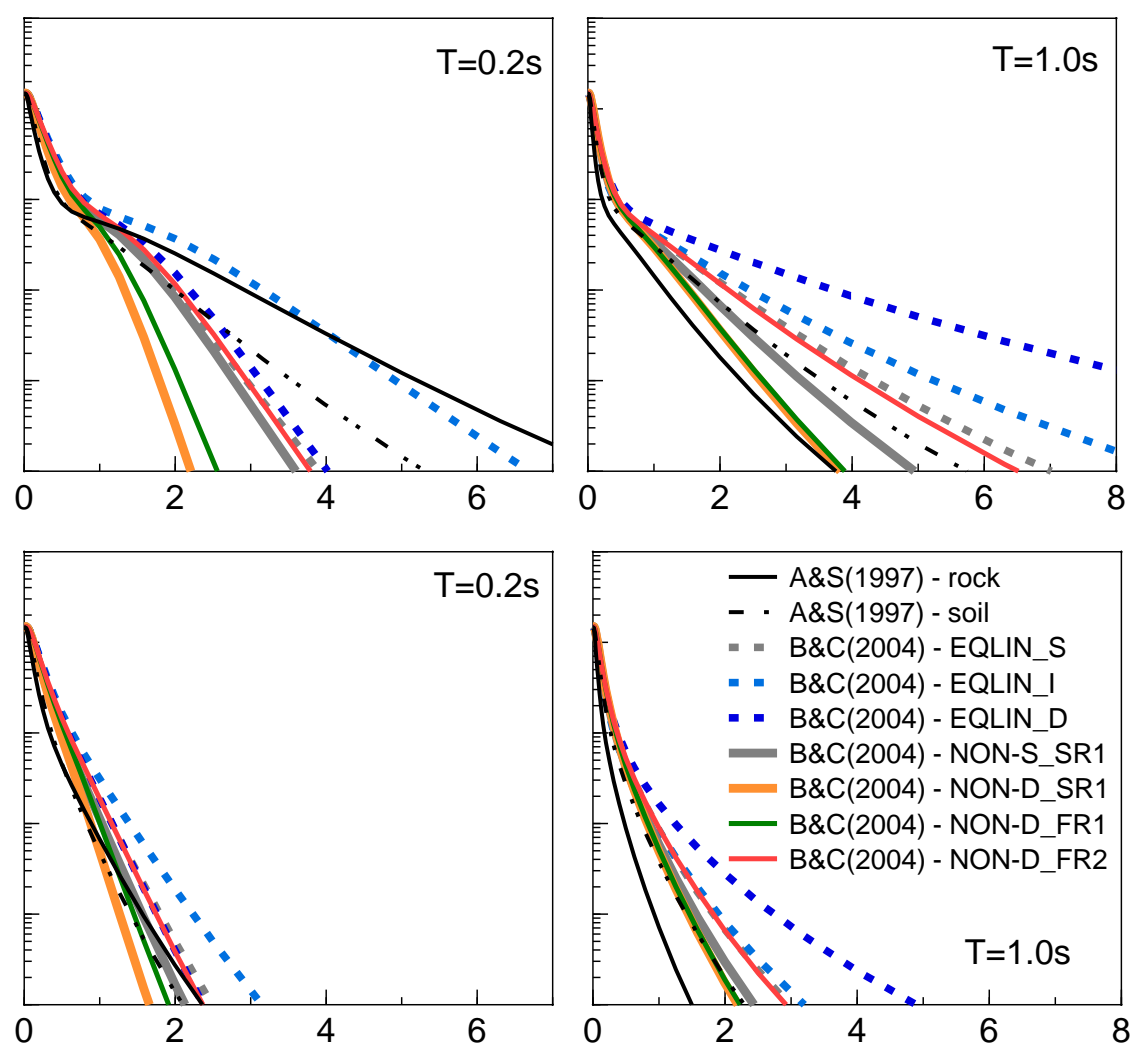

Surface Spectral Acceleration, $\mathrm{S}_{\mathrm{a}}^{\mathrm{s}}(\mathrm{g})$

Surface Spectral Acceleration, $\mathrm{S}_{\mathrm{a}}^{\mathrm{s}}(\mathrm{g})$ 

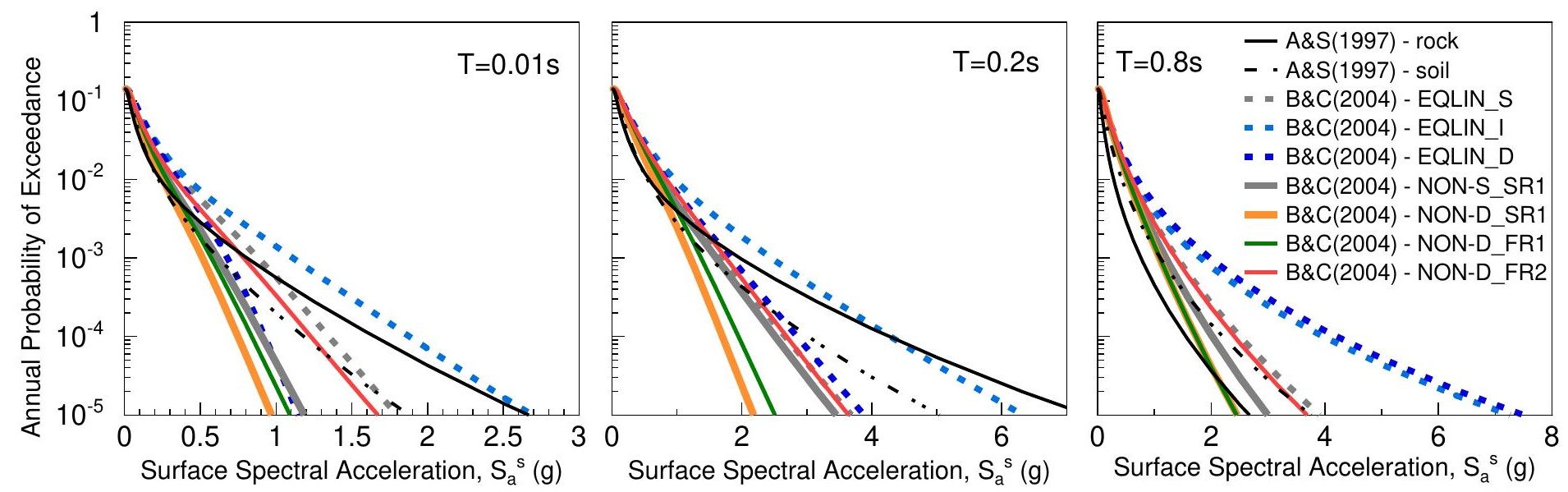


\section{Figure 21}

Click here to download high resolution image

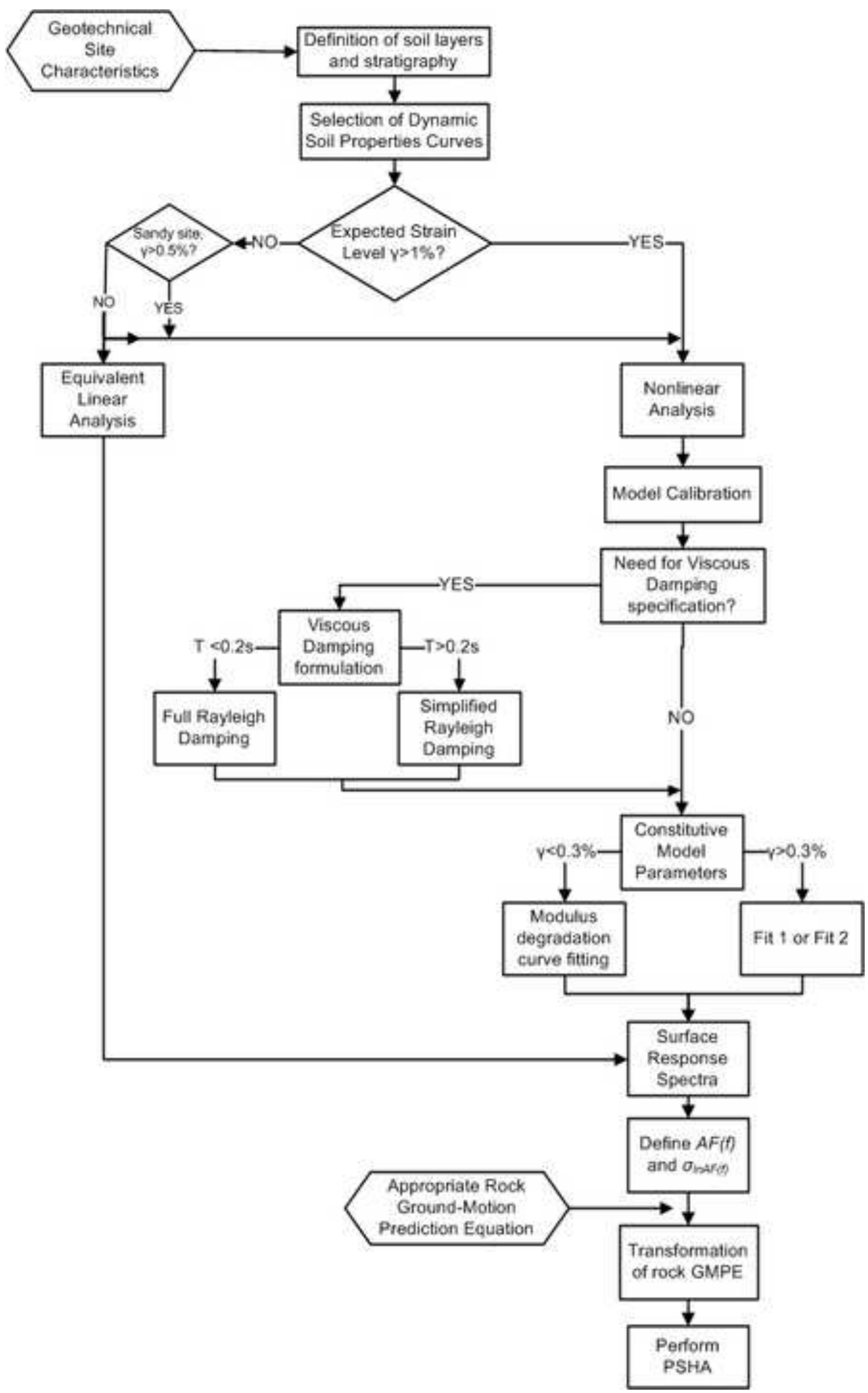

